Revista de Derecho

de la Pontificia Universidad Católica de Valparaíso

LV (Valparaíso, Chile, 2do semestre de 2020)

[pp. 225-259]

\title{
LA PUBLICIDAD COMERCIAL DIRIGIDA AL CONSUMIDOR FINANCIERO: UNA SISTEMATIZACIÓN DE SU REGULACIÓN Y DE LAS CONSECUENCIAS DERIVADAS DE SU VUlneración EN El Derecho Chileno*
}

[Commercial Advertising Aimed at the Financial Consumer: An Systematization of its Regulation and of the Consequences Derived from its Vulneration in the Chilean Law]

\section{Patricia Verónica López Díaz Universidad Diego Portales}

\section{RESUMEN}

El objetivo de este artículo es examinar la regulación de la publicidad comercial dirigida al consumidor financiero en nuestro ordenamiento jurídico, específicamente en la Ley 19.496 sobre Protección de los Derechos de los Consumidores (LPC) y en la normativa reglamentaria dictada en cumplimiento del artículo 62 de dicha ley, así como la tutela que debe dispensársele frente a los ilícitos publicitarios tipificados en ellas o que pueden desprenderse de algunos de sus preceptos. El método utilizado es el sistemático y el jurisprudencial, dado que se analizan los artículos de la LPC y los Reglamentos que disciplinan la publicidad dirigida al consumidor financiero, además de las escasas sentencias que han fijado el alcance de dichos preceptos.

\section{Abstract}

The objective of this article is to examine the regulation of commercial advertising aimed at financial consumers in our legal system, specifically in Law 19.496 on the Protection of Consumer Rights (LPC) and in the regulatory regulations issued by mandate of article 62 of that law, as well as the protection to be dispensed against the illicit advertising typified in them or that may be derived from some of its precepts. The method used is systematic and jurisprudential, given that those of the LPC and the Regulations that govern advertising directed to the financial consumer are analyzed, in addition to the few judgments that have set the scope of said precepts.

* Este trabajo forma parte del Proyecto FONDECYT Regular No 1190200 "La publicidad comercial como fenómeno jurídico: diversidad de problemas y perspectivas de solución en el derecho chileno" del que la autora es Investigadora Responsable. Licenciada en Ciencias Jurídicas y Sociales Universidad Adolfo Ibáñez. Doctora en Derecho Pontificia Universidad Católica de Valparaíso. Profesora de Derecho Civil Universidad Diego Portales, Santiago, Chile.Correo electrónico: patriciaveronica.lopezdiaz@mail.com. 
El resultado obtenido es la identificación de la publicidad engañosa y de la publicidad agresiva y la sistematización de la tutela aplicable en tales supuestos como mecanismos que permiten otorgar una efectiva tutela a dicho consumidor.

\section{Palabras clave}

Consumidor financiero - publicidad agresiva - publicidad comercial - publicidad engañosa - tutela del consumidor.
The result obtained is the identification of misleading advertising and aggressive advertising and the systematization of the applicable protection in such cases as mechanism to provide an effective protection to this consumer.

\section{KeYwORDS}

Agressive advertising - commercial advertising - consumer protection - financial consumer - misleading advertising.

RECIBIDO el 28 de septiembre de 2020 y ACEPTADO el 31 de enero de 2021

\section{INTRODUCCIÓN}

Un examen de nuestra literatura jurídica revela que la publicidad comercial constituye un tópico que no ha concitado especialmente la atención de la doctrina nacional, desinterés que probablemente se explique por la ausencia de un estatuto general y particular que la regule. En efecto, fue recién en el año 2007 en que comenzó a abordarse decididamente la publicidad, en la etapa precontractual de las relaciones de consumo ${ }^{1}$, focalizándose el análisis con mayor intensidad en la publicidad engañosa y en la integración publicitaria ${ }^{2}$ y más recientemente en los principios de la publicidad comercial perfilándolos como límites

${ }^{1}$ Momberg Uribe, Rodrigo. El rol de la publicidad en la etapa precontractual de los negocios de consumo y su relación con el principio de buena fe, en Corral, Hernán y Rodríguez, María Sara (coords.), Estudios de Derecho Civil II (Santiago, Editorial Lexis Nexis, 2007), pp. 593-608.

${ }^{2}$ IsLer Soto, Erika Marlene. Aproximación a la publicidad engañosa, desde la perspectiva de la competencia desleal y la protección al consumidor", en Revista Ars Boni et Aequi $6 \mathrm{~N}^{\circ} 1$ (2010), pp. 125-148, De la MaZa Gazmuri, Iñigo. "Artículo 28”, en De la Maza, Iñigo- y Pizarro, Carlos (dirs.), Barrientos, Francisca (coord.), La Protección de los Derechos de los Consumidores. Comentario a la Ley de Protección a los derechos de los consumidores (Santiago, Editorial Thomson Reuters, 2013), pp. 653671, López Díaz, Patricia Verónica. Publicidad Engañosa. Indemnización de daños. Concurrencia de responsabilidad civil. Opción de responsabilidades. Responsabilidad Extracontractual. Corte Suprema, 18 de enero de 2018, rol 73907-2016, en Revista Chilena de Derecho Privado 30 (2018), pp. 195-210, González Cazorla, Fabián, Daño moral en el derecho del consumidor (Santiago, Editorial Der, 2019), 81-90, BARRIENTOS Camus, Francisca. Lecciones de derecho del consumidor (Santiago: Thomson Reuters, 2019), pp. 65-75 y López Díaz, Patricia Verónica. La tutela de la publicidad engañosa: un intento de sistematización desde el derecho civil chileno, en ELORRIAGA, 
del mensaje publicitario cuya infracción permite construir la publicidad ilícita y distinguir las categorías específicas que ella comprende 3 . Este último tópico ha trascendido incluso el mero interés doctrinario como lo revelan el documento "Análisis, Vigilancia y Gestión jurídica de la publicidad en Chile" de abril de 2017 elaborado por el Departamento de Estudios e Inteligencia del Servicio Nacional del Consumidor (SERNAC) ${ }^{4}$ que formula tales principios y la Circular Interpretativa sobre Publicidad y Prácticas Comerciales (CIPP) dictada por dicho organismo el 21 de marzo de $2019^{5}$ que les otorga un sustrato dogmático más acabado.

Otro tanto ha ocurrido con el consumidor financiero, pues si bien los esfuerzos se han orientado a ponderar la eficacia de la tutela que le otorga la LPC a partir de las modificaciones introducidas por la Ley 20.555 de 2011, solo en los últimos años se ha abordado la mediación y el arbitraje financiero como mecanismos de solución de controversias entre consumidores y proveedores ${ }^{6}$. La obligación precontractual de la entidad financiera de informar al cliente ${ }^{7}$ y más profusamente el sobreendeudamiento de dicho consumidor en tres direcciones. La primera ha consistido en explorar herramientas como el big data y el fintech -propias del modelo de préstamo responsable- para dar cumplimiento a los deberes de consejo y adecuación del proveedor financiero ${ }^{8}$ e impedir el sobreendeudamiento

Fabián (coord.), Estudios de Derecho Civil XV (Santiago, Editorial Thomson Reuters, 2020), pp. 839-865.

${ }^{3}$ Una revisión de este tópico en López DíAz, Patricia Verónica. La publicidad comercial como fenómeno jurídico: una aproximación general desde el derecho chileno, en: Revista Ius et Praxis 26, No 3 (2020), pp. 23-44

${ }^{4}$ Disponible en https://www.sernac.cl/portal/619/articles-5386_archivo_01.pdf. [Fecha de consulta: 31 de julio de 2020].

${ }^{5}$ Disponible en https://www.sernac.cl/portal/618/articles-9190_archivo_01.pdf. [Fecha de consulta: 31 de julio de 2020].

${ }^{6}$ Yáñez Rebolledo, María Paz. Protección al consumidor financiero en Chile. Mi experiencia como árbitro y mediadora del Sernac Financiero, en Carrasco, Humberto (edit.), Estudios de Derecho del Consumidor (Santiago, Rubicón Editores, 2018).

${ }^{7}$ Véase Hernández Paulsen, Gabriel. La obligación precontractual de la entidad financiera de informar al cliente, especialmente a la luz de la Ley de Protección de los Derechos de los consumidores" en VIDAL, Álvaro; Severin, Gonzalo; Mejías, Claudia (editores), Estudios de Derecho Civil X (Santiago, Editorial Thomson Reuters, 2015), pp. 351-373, quien analiza el contenido de tal obligación y las consecuencias jurídicas derivadas de su vulneración.

${ }^{8}$ Sobre tales deberes Goldenberg Serrano, Juan Luis. Los contornos del deber de consejo como expresión de la colaboración y como técnica de protección, Revista de Derecho Universidad de Concepción, Vol. 86, Nº 244 (2018), pp. 9-41, López DíAz, Patricia Verónica ¿Es la obligación/deber de advertencia una categoría exclusiva de la Ley 19.496?: hacia una justificación dogmática y propuesta de construcción en el Código 
o mitigarlo una vez ocurrido'. La segunda ha tratado los paradigmas del consumidor financiero responsable y del proveedor financiero profesional para modular el estándar de diligencia esperable de dicho consumidor en el ordenamiento jurídico nacional, imponiendo a este último ciertos deberes preventivos para evitar su insolvencia y sugiriendo enfocar el análisis desde la lógica de corresponsabilidad, esto es, de la existencia de una relación colaborativa entre deudores y acreedores ${ }^{10}$. La tercera ha indagado el propósito persuasivo de la publicidad y sus peligros en el ámbito del crédito al consumo, postulando que ella induce a los consumidores a adoptar decisiones subóptimas, como el sobreendeudamiento, y que el legislador desatiende los problemas derivados de su racionalidad imperfecta ${ }^{11}$.

El análisis de la publicidad comercial dirigida al consumidor financiero se ha direccionado, entonces, a cómo ella lo incita o persuade para adoptar la decisión de contratar un determinado producto o servicio, mas no se ha examinado detenidamente su regulación, en qué supuestos deviene en ilícita y en qué consiste jurídicamente la ilicitud que en ella subyace ni la tutela que puede activarse en tal caso. La única alusión que hemos encontrado se refiere a la publicidad engañosa disciplinada en el artículo 17L de la LPC arduamente criticado por alejarse de lo preceptuado en el artículo 28 de dicha Ley ${ }^{12}$. Cuestionamiento que, como tendremos ocasión de analizar, se diluye si se le examina a partir de la noción de publicidad engañosa acuñada por nuestra doctrina más reciente. A ello se agrega que además de la publicidad engañosa puede existir otra categoría de publi-

Civil chileno, en Gómez, Maricruz; Hernández, Gabriel; Lathrop, Fabiola, TAPIA; Mauricio (edits.), Estudios de Derecho Civil XIV (Santiago, Editorial Thomson Reuters, 2019), pp. 929-958 y GoldenberG SerRano, Juan Luis. El crédito de consumo ofrecido al consumidor vulnerable: el deber de adecuación como parte de un modelo de corresponsabilidad del proveedor en ELORRIAGa, Fabián (coord.), Estudios de Derecho Civil XV (Santiago, Editorial Thomson Reuters, 2020), pp. 818-838.

${ }^{9}$ Goldenberg Serrano, Juan Luis. Herramientas del big data y del fintech para prevenir y aliviar el sobreendeudamiento del consumidor: una propuesta, en Revista Chilena de Derecho y Tecnología 8, N² (2019), pp. 5-32.

${ }^{10}$ Goldenberg SerRano, Juan Luis. El sobreendeudamiento y los paradigmas del consumidor financiero responsable y del proveedor financiero profesional, en: Revista Ius et Praxis 26, $\mathrm{N}^{\circ} 1$ (2020), pp. 1-27.

${ }^{11}$ Goldenberg Serrano, Juan Luis. El propósito persuasivo de la publicidad y sus peligros en el ámbito del crédito al consumo, en Revista Chilena de Derecho Privado 34 (2020), pp. 163-204.

${ }^{12}$ Fernández Acevedo, Fernando. Artículo $17 L$, en De la Maza, Iñigo- y Pizarro, Carlos (dirs.), Barrientos, Francisca (coord.), La Protección de los Derechos de los Consumidores. Comentario a la Ley de Protección a los derechos de los consumidores (Santiago, Editorial Thomson Reuters, 2013), pp. 504-512. 
cidad ilícita respecto del consumidor financiero, cual es la publicidad agresiva, que se infiere de ciertos preceptos de la LPC y, por lo mismo, requiere ser examinada.

Se trata, como se advierte, de un tópico inexplorado en nuestra doctrina que conviene comenzar a abordar al menos por dos razones. En primer lugar, porque las altas tasas de sobreendeudamiento de la población chilena pueden explicarse, en parte, por la deficiente regulación de la publicidad financiera, dado que ella no desincentiva ni reprime contundentemente al proveedor frente a los ilícitos publicitarios que realice o que pueda llegar a realizar. En segundo lugar, porque este desafío permite seguir avanzando en el análisis dogmático que hasta ahora se ha efectuado de la protección del consumidor financiero, toda vez que exige determinar si la publicidad ilícita adquiere alguna configuración especial respecto de este tipo de consumidor (como acontece con los menores de edad ${ }^{13}$ ) y precisar el alcance de la tutela que el legislador le dispensa frente a dicha publicidad.

Para alcanzar nuestro propósito dividiremos este artículo en tres secciones. En la primera cotejaremos la figura del consumidor financiero con la del consumidor general para establecer ante qué categoría de consumidor nos encontramos. Seguidamente examinaremos la regulación de la publicidad dirigida al consumidor financiero, sistematizando las especies de publicidad ilícita que pueden desprenderse de la LPC y de los Reglamentos que disciplinan dicha publicidad, analizando su regulación y las sentencias que se han pronunciado sobre tales preceptos. Finalmente, abordaremos la tutela que debe otorgársele a dicho consumidor frente a este tipo de prácticas publicitarias, identificando las normas sobre las que puede erigirse en la LPC y en el Código Civil, según el caso, y precisando su alcance (iii). Examinados tales tópicos, formularemos las conclusiones.

\section{EL CONSUMIDOR FINANCIERO COMO UNA FIGURA CONTRAPUESTA AL} CONSUMIDOR GENERAL

Una revisión de la dogmática comparada revela que la noción de consumidor ha empezado a admitir diversas clasificaciones en atención a la diligencia exigible y a la información que este posee para adoptar sus

${ }^{13}$ Que constituyen una categoría de consumidores hipervulnerables, dado que a su vulnerabilidad estructural se añade otra representada por su edad. Sobre la publicidad dirigida a ellos y la tutela que debe otorgárseles véase LópEz DíAz, Patricia Verónica. La publicidad abusiva como ilícito que vulnera la integridad del consumidor $e$ infringe el derecho a la seguridad en el consumo previsto en el artículo 3 letra d.) de la LPC, en IsLer Soto, Erika (editora), Seguridad y conformidad en el derecho de consumo: reflexiones actuales (Valencia, Tirant Lo Blanch, en prensa). 
decisiones, distinguiéndose al efecto el consumidor común, el consumidor informado o sofisticado y el consumidor especialmente vulnerable, hipervuln erable, con doble vulnerabilidad o con vulnerabilidad agravada ${ }^{14}$. Esta última categoría incluso ha sido objeto de sistematización en el derecho comparado, diferenciándose la vulnerabilidad endógena y permanente, la vulnerabilidad temporal y la vulnerabilidad episódica en la Resolución del Parlamento Europeo de 22 de Mayo de 2012 sobre una Estrategia de Refuerzo de los Derechos de los Consumidores ${ }^{15}$ y recientemente se ha recogido en la Resolución 139/2020 de 28 de mayo de 2020 de la Secretaría de Comercio Interior argentina ${ }^{16}$

\footnotetext{
${ }^{14}$ En tal sentido véase Hernández Díaz- Ambrona, María Dolores, Consumidor vulnerable (Madrid, Editorial Reus, 2016) y Hualde MAnso, Teresa. Consumidor medio y consumidor vulnerable, en HUALDE Teresa, Del consumidor informado al consumidor real. El futuro del Derecho de consumo europeo (Madrid, Editorial Dykinson, 2016), pp. 31-54 y BAROCELli, Sergio Sebastián. Hacia la construcción de la categoría de consumidores hipervulnerables en BAROCELLI, Sergio Sebastián (dir.), Consumidores Hipervulnerables (Buenos Aires, El Derecho, 2018), pp. 11-15. En contra de esta fragmentación del consumidor medio RojAs Covarrubias, Nicolás ¿Es el consumidor un mal padre de familia? Alcance del deber de cuidado exigible a los consumidores" en Vidal, Álvaro; Severin, Gonzalo; Mejías, Claudia (editores), Estudios de Derecho Civil X (Santiago, Editorial Thomson Reuters La Ley, 2015), pp. 413-431.

${ }^{15}$ Disponible en https://www.europarl.europa.eu/doceo/document/TA-7-20120209_ES.html?redirect. En lo que concierne a esta tipología véase AGUILAR OlIVARES, Yolanda. Las prácticas agresivas desleales en el mercado y la tutela del consumidor (Navarra, Editorial Aranzadi, 2020), p. 73. La autora explica que la vulnerabilidad endógena y permanente es aquella que obedece a circunstancias personales asociadas a una discapacidad mental y síquica; la temporal es la vulnerabilidad en que el consumidor se encuentra en un estado y situación personal que lo alejan de su entorno, como la educación o situación social; y la episódica es aquella transitoria en que cualquier consumidor puede encontrarse durante su vida.

${ }^{16}$ Dicha resolución indica que en su artículo $1^{\circ}$ que, para los fines previstos en el artículo 1 de la Ley $\mathrm{N}^{\circ} 24.240$ (Ley de Defensa del Consumidor) se consideran consumidores hipervulnerables, en cuanto personas naturales, a "aquellos consumidores que sean personas humanas y que se encuentren en otras situaciones de vulnerabilidad en razón de su edad, género, estado físico o mental, o por circunstancias sociales, económicas, étnicas y/o culturales, que provoquen especiales dificultades para ejercer con plenitud sus derechos como consumidores". Por su parte, el artículo segundo señala que "podrán constituir causas de hipervulnerabilidad, entre otras, las siguientes condiciones: a) reclamos que involucren derechos o intereses de niños, niñas y adolescentes; b) ser personas pertenecientes al colectivo LGBT+ (lesbianas, gays, bisexuales y transgénero); c) ser personas mayores de 70 años; d) ser personas con discapacidad conforme certificado que así lo acredite; e) la condición de persona migrante o turista; f) la pertenencia a comunidades de pueblos originarios; g) ruralidad; h) residencia en barrios populares conforme Ley $\mathrm{N}^{\circ} 27.453$; i) situaciones
} 
y en el artículo 3 de un Anteproyecto de Ley de Defensa del Consumidor cuyo propósito es reemplazar la actualmente vigente ${ }^{17}$.

Claro está que, por regla general, todo consumidor es la parte débil de la relación de consumo, pues se asume que este tiene una vuln erabilidad estructural que descansa, como lo indica Barocelli ${ }^{18}$, en factores técnicos (no tiene conocimientos respecto del bien que adquiere o el servicio que contrata), jurídicos o científicos (se le imponen contratos de adhesión y condiciones generales de la contratación), socioe co nómicos, materiales o fácticos (ostenta una posición de inferioridad respecto del proveedor en estos ámbitos), sicológicos (es destinatario de la publicidad, de prácticas comerciales y de marketing), informativo (atendida la asimetría respecto del proveedor), de acceso a la justicia (dado que frecuentemente no obtiene respuestas eficaces, rápidas y justas), biológicos (pues la satisfacción de sus necesidades básicas le exige consumir), políticos (el poder de organización del proveedor es ostensiblemente mejor) y ambientales (porque con cierta frecuencia es destinatario de ofertas que presentan daños al medio ambiente).

Puede ocurrir que nos encontremos ante el consumidor medio, esto es, el que, a pesar de suvulnerabilidad estructural, está "normalmente informado, razonablemente atento y perspicaz y es capaz de interpretar y procesar correctamente la información que recibe"19, categoría que se ha recepcionado en nuestra dogmática a partir de los artículos 20, 3 bis

de vulnerabilidad socio-económica acreditada por alguno de los siguientes requisitos:1) Ser Jubilado/a o Pensionado/a o Trabajador/a en Relación de Dependencia que perciba una remuneración bruta menor o igual a DOS (2) Salarios Mínimos Vitales y Móviles;2) Ser Monotributista inscripto en una categoría cuyo ingreso anual mensualizado no supere en DOS (2) veces el Salario Mínimo Vital y Móvil; 3) Ser Beneficiario/a de una Pensión No Contributiva y percibir ingresos mensuales brutos no superiores a DOS (2) veces el Salario Mínimo Vital y Móvil; 4) Ser beneficiario/a de la Asignación por Embarazo para Protección Social o la Asignación Universal por Hijo para Protección Social; 5) Estar inscripto/a en el Régimen de Monotributo Social; 6) Estar incorporado/a en el Régimen Especial de Seguridad Social para empleados del Servicio Doméstico (Ley 26.844); 7) Estar percibiendo el seguro de desempleo; 8) Ser titular de una Pensión Vitalicia a Veteranos de Guerra del Atlántico Sur (Ley N $\left.{ }^{\circ} 23.848\right)$ ). Dicha Resolución se encuentra disponible en el sitio web https:/www.boletinoficial.gob.ar/detalleAviso/primera/229875/20200528.

${ }^{17}$ Dicho precepto expresa lo siguiente: "Consumidores con vulnerabilidad agravada. El principio de protección del consumidor se acentúa tratándose de colectivos sociales con vulnerabilidad agravada. En tales supuestos, en el marco de la relación de consumo, la educación, la salud, la información, el trato equitativo y digno y la seguridad deben ser especialmente garantizados".

${ }^{18}$ Quien explora cada uno de ellos en Barocelli, Sergio, cit. (n. 14), pp. 13-15.

${ }^{19}$ Un completo análisis en Hualde, Teresa, cit. (n. 14), pp. 11-54. 
letra b) y $1 \mathrm{~N}^{\circ} 1$ y $2^{20}$, pero que, como veremos, se ha criticado respecto del consumidor financiero ${ }^{21}$. O ante un consumidor sofisticado que no presenta asimetrías de información sino que incluso está más informado que el propio proveedor respecto del bien a adquirir o el servicio a contratar, deviniendo en tal caso la referida vulnerabilidad estructural en presun ta $^{22}$, pudiendo acreditar el proveedor que ella no concurre, desvirtuándola.

Cuestión distinta es que a esa capa de vulnerabilidad se agregue otra derivada de una situación personal del consumidor, pues en tal supuesto éste será hipervulnerable. Así acontecerá si a su vulnerabilidad estructural se añade una adicional que encuentra su causa en su edad, condición psicofísica, de género, socioeconómica o cultural o en otras circunstancias permanentes o transitorias. De allí que se sostenga que pertenecen a esta especie de consumidores los infantes, los adolescentes, la mujer, las personas con necesidades alimentarias especiales, el adulto mayor, los pueblos indígenas, el turista, el consumidor electrónico y las minorías religiosas ${ }^{23}$.

La pregunta que surge, entonces, es a cuál de estas categorías puede reconducirse el consumidor financiero. Y, para responderla, resulta útil recurrir, a falta de definición legal en nuestro ordenamiento jurídico ${ }^{24}$, a

${ }^{20}$ Tales preceptos se refieren a la garantía legal (art. 20), el derecho a retracto del consumidor (art. 3 bis letra b) y a la noción de consumidor y proveedor (artículo 1 $\mathrm{N}^{\circ} 1$ y 2), derivándose de estas últimas el carácter oneroso del contrato de consumo que permite, inferir, por tanto, que la diligencia exigida es la ordinaria. Véase IsLER Sото, Erika. La relatividad de los derechos subjetivos de los consumidores, en Revista Derecho de Valdivia 24, № 2 (2011), pp. 77-80.

${ }^{21}$ Pues se ha estimado que la racionalidad imperfecta de los consumidores haría ilusoria esta categoría para el financiero, atendida la complejidad y sofisticación de la información que recibe, proponiéndose un modelo de corresponsabilidad que exige superar los meros deberes de información del proveedor reformulándolos como deberes de consejo, adecuación y advertencia (GoldenkERG, Juan, El sobreendeudamiento y los paradigmas..., cit. (n.10), pp. 1-27).

${ }^{22} \mathrm{La}$ presunción de vulnerabilidad respecto de todos los consumidores ciertamente es una consecuencia del principio pro consumatore sobre el que se erige el derecho de consumo. Un contundente análisis de este principio en el derecho chileno en IsLER Soto, Erika. Derecho del consumo. Nociones fundamentales (Valencia, Editorial Tirant lo Blanch, 2019), pp. 112-138.

${ }^{23}$ Un detenido estudio de esta categoría en Barocelli, Sergio, cit. (n. 14), pp. 9-32. En nuestra dogmática la única autora que la ha explorado es la profesora Erika Isler, justificando su pertinencia y exponiendo sus criterios de determinación (véase IsLer Soto, Erika. Acerca del reconocimiento de los consumidores hipervulnerables, en VÁsquez, María Fernanda (dir.) Estudios de Derecho Comercial, X Jornadas Nacionales de Derecho Comercial (Valencia, Editorial Tirant lo Blanch, 2020), pp.197-214

${ }^{24}$ Como acontece, por ejemplo, en el ordenamiento jurídico colombiano en que 
la noción que se ha acuñado a partir de las normas contenidas en la LPC que entiende por tal a "la persona natural o jurídica que en calidad de destinatario final celebre un contrato de servicios crediticios, de seguros $\mathrm{y}$, en general, de cualquier producto financiero, ya sea con un banco, con una institución financiera, una sociedad de apoyo a su giro, un establecimiento comercial, una compañía de seguros, una caja de compensación, una cooperativa de ahorro y crédito, o, en general, con cualquier persona natural o jurídica proveedora de dichos servicios o productos" 25 .

Pues bien, nuestra impresión es que, salvo que el consumidor financiero tenga perfecto conocimiento de los productos y servicios financieros que pretende adquirir o contratar y entienda los instrumentos financieros a lo que la publicidad alude, se trata de un consumidor hipervulnerable, toda vez que a su vulnerabilidad estructural se añade otra tem poral que lo llevará a adquirir productos financieros y servicios crediticios, cual es la situación socioeconómica en que se encuentra, a la que puede agregarse, según el caso, su nivel de educación que le hará mucho más difícil comprender el detalle y la complejidad de la información que se le proporciona, alejándolo de su realidad o entorno ${ }^{26}$.

Existen al menos tres consideraciones que avalan tal constatación y que se refieren a la necesidad legislativa de extremar la tutela de este tipo de consumidor y a la vulnerabilidad cognitiva y alfabética que este presenta. La primera es que el año 2011 tuvo que dictarse la Ley 20.555 para fortalecer

la Ley 1328 de 2009 que dicta normas en materia financiera, de seguros, del mercado de valores y otras disposiciones, que lo define en su artículo $2 \mathrm{~d}$ ) como "todo cliente, usuario o cliente potencial de entidades vigiladas", entendiendo por estas últimas, según el literal h) de dicho precepto "las entidades sometidas a inspección y vigilancia de la Superintendencia Financiera de Colombia".

${ }^{25}$ Por todos San Martín Neira, Lilian. Artículo $3^{\circ}$ inciso $2^{\circ}$, en Iñigo De la Maza, Carlos Pizarro (edits.), Francisca Barrientos (coord.). La Protección de los Derechos de los Consumidores. Comentario a la Ley de Protección a los derechos de los consumidores (Santiago, Editorial Thomson Reuters, 2013), pp. 141-143.

${ }^{26}$ Complejidad técnica que ya había sido denunciada en Lema Devesa, Carlos y Fernando Magarzo, María del Rosario. La publicidad Financiera en Lema Devesa, Carlos, Problemas jurídicos de la publicidad (Madrid, Marcial Pons, 2007), pp. 433-445.-4 Acuñando esta denominación Aguilar, Yolanda, cit. (n. 15), p. 73 y el punto B. de la Resolución del Parlamento Europeo de 22 de Mayo de 2012 sobre una Estrategia de Refuerzo de los Derechos de los Consumidores. Admitiendo también dichos factores como determinantes de la hipervulnerabilidad destacan, entre otros, Hernández Díaz- Ambrona, María Dolores, cit. (n. 14), p. 39, Hualde, Teresa, cit. (n. 14), p. 35 y Barocelli, Sergio, cit. (n. 14), p. 16, Isler Soто, Erika. Acerca del reconocimiento..., cit. (n. 23), pp.197-214 y la Resolución 139/2020 de 28 de mayo de 2020 de la Secretaría de Comercio Interior argentina reproducida en la nota 16 de este artículo. 
la tutela del consumidor financiero que, además de incorporar diversos literales al artículo 17 de la LPC para regular la información técnica que debía proporcionárseles, añadió un inciso segundo al artículo 3 de dicha ley que tipificó sus derechos con el propósito de mitigar la asimetría informativa de la que podía ser víctima si sólo resultaba aplicable el artículo 3a) de la $\mathrm{LPC}^{27}$, sin perjuicio de que el exceso de dicha información haya configurado una paradoja regulatoria que termina por desprotegerlos ${ }^{28}$.

La segunda es que ha existido una especial preocupación del legislador por disciplinar la publicidad dirigida al consumidor financiero, consagrando los principios de veracidad y de transparencia publicitaria y determinadas especies de publicidad ilícita, lo que no acontece tratándose de otros consumidores. Así lo revelan, como lo examinaremos en el próximo apartado, los artículos $17 \mathrm{G}$ relativo a la publicidad de la CAE, 17L de la LPC a propósito de la publicidad engañosa, $17 \mathrm{~F}$ que repudia el envío de productos o contratos representativos de ellos no solicitados a su domicilio o lugar de trabajo, $17 \mathrm{H}$ referente a las ventas atadas. Además el artículo 62 de dicha Ley que impone la obligación de dictar Reglamentos que disciplinen, entre otras materias, la publicidad dirigida a ellos, aprobados por los Decretos Supremos del Ministerio de Economía, Fomento y Turismo $\mathrm{N}^{\circ} 42, \mathrm{~N}^{\circ} 43$ y $\mathrm{N}^{\circ} 44$ que contienen, respectivamente, el Reglamento sobre Información de Créditos Hipotecarios, de Créditos de Consumo y de Tarjetas de crédito bancarias y no bancarias ${ }^{29}$.

${ }^{27}$ Un análisis de los derechos de los consumidores financieros en SAN MARTín, Lilian, cit. (n. 25), pp. 143-150.

${ }^{28}$ Sobre este tópico véase De la Maza Gazmuri, Iñigo. La información como técnica de protección de los consumidores: créditos hipotecarios ¿una paradoja regulatoria?, en Vidal, Álvaro; Severin, Gonzalo; Mejías, Claudia (editores), Estudios de Derecho Civil X (Santiago, Editorial Thomson Reuters, 2015), pp. 375-396.

${ }^{29}$ Un fenómeno similar se advierte incluso en ordenamientos jurídicos como el español que tiene una ley especial sobre publicidad comercial, pues la regulación de la publicidad financiera ha sido dispersa y no siempre se ha contenido en leyes. Así la publicidad de las entidades de crédito está regulada en el artículo 48.2 de la Ley 26/1988 de 29 de julio sobre Disciplina e Intervención de las Entidades de Crédito y en el Decreto 240/2003 de 14 de octubre sobre Cajas de Ahorro y la Circular 8/1990 del Banco de España; la publicidad de valores en el artículo 94 de la Ley 24/1988 de 28 de julio del Mercado de Valores y en el artículo 22 del Real Decreto 291/1992 de 27 de marzo sobre Emisiones y Ofertas públicas de Venta de Valores; la publicidad de instituciones de inversión colectiva en el artículo 94 de la Ley de Mercado de Valores y en el Código General de Conducta Publicitaria de las Instituciones de Inversión Colectiva y Fondos de Pensiones (un análisis de esta normativa en Lema Devesa, Carlos y Fernando Magarzo, María del Rosario, cit. (n. 26), pp. 433-445) y en Leiñena Mendizabal, Elena y Irákulis Arregi, Nerea, $\mathrm{La}$ regulación jurídica de la publicidad financiera, Estudios sobre Consumo $\mathrm{N}^{\circ} 80$ (2007), 
Y la tercera es que aunque el modelo debiera ser el de consumidor medio, el consumidor financiero, como lo ha precisado acertadamente el profesor Juan Luis Goldenberg ${ }^{30}$, no es aquel "normalmente informado, razonablemente atento y perspicaz, capaz de interpretar y procesar correctamente la información que recibe", pues presenta fuertes sesgos cognitivos y analfabetismo que no sólo acentúan su vulnerabilidad y persuasión sino que develan una racionalidad imperfecta que lo lleva adoptar decisiones subóptimas, fenómeno que exige superar los meros deberes de información y reformularlos como deberes de consejo y de adecuación y propiciar un modelo de corresponsabilidad.

\section{LA REGULACIÓN DE LA PUBLICIDAD COMERCIAL DIRIGIDA AL}

\section{CONSUMIDOR FINANCIERO Y LAS CONSECUENCIAS DE SU INOBSERVANCIA}

Una revisión de la normativa, que regula la publicidad comercial en nuestro ordenamiento jurídico, devela que aquella dirigida al consumidor financiero se encuentra disciplinada a nivel legal y a nivel reglamentario y, como examinaremos en las líneas que siguen, contiene normas generales relativas al contenido de dicha publicidad y a los principios a los que ella debe sujetarse y normas que disciplinan directamente ciertos ilícitos publicitarios o permiten sentar las bases para sustentar su procedencia. En ese mismo orden las examinaremos.

Con todo, previo a analizarla, debemos establecer qué entenderemos por publicidad, dado que la diversidad de definiciones existentes en nuestro ordenamiento jurídico exige arribar a una noción unitaria. $\mathrm{Y}$ es que no sólo el artículo $1 \mathrm{~N}^{\circ} 4$ de la LPC la define ${ }^{31}$ sino que también acometen este desafío el inciso segundo del artículo 7 de la Ley 20.606 sobre Com-

pp. 9-28). A ellas se agrega el artículo 6 de la Ley5/2019, de 15 de marzo sobre contratos de crédito inmobiliario que regula la información básica que debe figurar en la publicidad de préstamos inmobiliarios, analizada con anterioridad a esta ley por Aguilar Ruíz, Leonor, La publicidad de créditos inmobiliarios: regulación jurídica y "solapamiento normativo" en SÁnchez Lería, Reyes-VÁsQuez PASTOR Jiménez, Lucía (coords.), Los contratos de crédito inmobiliario. Algunas soluciones legales (Madrid, Editorial Reus, 2018), pp. 47-60 y una vez que entró en vigencia por BARRAL VIÑALS, Inmaculada, Los contratos de crédito inmobiliario: control de transparencia vs control de abusividad (Cizur Menor, Editorial Thomson Reuters, 2020).

${ }^{30}$ Goldenberg, Juan, El sobreendeudamiento y los paradigmas..., cit. (n.10), pp. 5-11 y GOLDENBERG, Juan, El crédito de consumo ofrecido al consumidor vulnerable..., cit. (n. 8), pp. 818-838.

${ }^{31}$ Este artículo entiende por publicidad "la comunicación que el proveedor dirige al público por cualquier medio idóneo al efecto, para informarlo y motivarlo a adquirir o contratar un bien o servicio, entendiéndose incorporadas al contrato las 
posición Nutricional de los alimentos y su Publicidad ${ }^{32}$ y el artículo 106 NN$^{\circ} 34$ del Reglamento Sanitario de Alimentos (Decreto MINSAL 977/96) que la reproduce, así como los artículos $3 \mathrm{~N}^{\circ} 38,3 \mathrm{~N}^{\circ} 40$ y $3 \mathrm{~N}^{\circ} 56$ de los Reglamento sobre Información de Créditos Hipotecarios, de Créditos de Consumo y de Tarjetas de crédito bancarias y no bancarias que reiteran aquella prevista en la $\mathrm{LPC}^{33}$, a las que se agrega la contenida en la Sección "Definiciones" del Código Chileno de Ética Publicitaria (CchEP) ${ }^{34}$.

Pues bien, considerando que todas ellas tienen como común denominador los elementos comunicación, medio de difusión y la finalidad, entenderemos por publicidad comercial toda forma de comunicación que tiene por propósito trasmitir, a través de cualquier medio idóneo al efecto un mensaje informativo en forma persuasiva con la intención de influir, en la toma de decisiones de sus destinatarios sobre la adquisición de un producto y/o la contratación de un servicio, sea motivándolos al efecto o promovien do dicho producto o servicio ${ }^{35}$. Será, entonces, esta la noción sobre la que erigiremos nuestro análisis en los siguientes apartados.

1. Normas generales relativas al contenido de la publicidad financiera y a los principios a los que ella debe sujetarse

La publicidad financiera, así como la tutela que debe dispensarse al consumidor financiero, no ha sido regulada por una Ley especial destinada al efecto sino que sólo existen normas generales contenidas en la LPC, incorporadas en virtud de la Ley 20.555, y en los Reglamentos dictados en cumplimiento del artículo 62 de dicha Ley sobre Información de Créditos

condiciones objetivas contenidas en la publicidad hasta el momento de celebrar el contrato".

${ }^{32}$ Este precepto señala lo siguiente: "Para los efectos de esta ley se entenderá por publicidad toda forma de promoción, comunicación, recomendación, propaganda, información o acción destinada a promover el consumo de un determinado producto".

${ }^{33}$ En efecto, tales artículos adaptan la noción de publicidad del artículo $1 \mathrm{~N}^{\circ} 4$ de la LPC, precisando que es la destinada a informar y motivar al público a contratar un crédito hipotecario, crédito de consumo o adquirir o contratar una tarjeta de crédito, según el caso.

${ }^{34}$ Que la define como "toda actividad o forma de comunicación dirigida al público o a un segmento del mismo, con el propósito de influir en sus opiniones o conductas, a través de cualquier medio, incluyendo promociones, placement y otras actividades o eventos realizados con fines promocionales, comerciales y/o de competir con otras alternativas".

${ }^{35}$ Sobre esta noción véase LópEz, Patricia. La publicidad comercial como fenómeno jurídico..., cit. (n. 3), pp. 26 a 28. 
Hipotecarios, de Créditos de Consumo y de Tarjetas de crédito bancarias y no bancarias a los que hemos aludimos más arriba.

En lo que se refiere a la LPC destaca únicamente el inciso primero del artículo $17 \mathrm{G}$ que exige a los proveedores financieros informar la CAE (carga anual equivalente) en toda publicidad de operaciones de crédito en que se informe una cuota o tasa de interés de referencia y que se realice por cualquier medio masivo o individual. Asimismo precisa que deberán otorgar a la publicidad de la CAE "un tratamiento similar a la de la cuota o tasa de interés de referencia, en cuanto a tipografía de la gráfica, extensión, ubicación, duración, dicción, repeticiones y nivel de audición. No se establece, entonces, una tipografía concreta para la CAE sino que, como lo han sugerido los profesores Mauricio Baquero y Guillermo Caballero, un parámetro, cual es, "las condiciones que el proveedor escoja para publicar la cuota o tasa de referencia”, asegurando así el legislador un mismo nivel de percepción por el consumidor de ambas informaciones y educándolo respecto de los costos asociados al crédito ${ }^{36}$.

Lo cierto es que una lectura más detenida nos permite arribar a una constatación adicional: dicho artículo, además de constituir una manifestación del deber del proveedor de educar para un consumo responsable -consagrado en el artículo 3 letra e) de la $\mathrm{LPC}^{37}$, constituye una manifestación del principio de transparencia publicitaria que promueve la comprensión del mensaje y que reviste trascendental importancia en la proscripción de la inducción a error del consumidor $y$, por consiguiente, de la publicidad engañosa. En efecto, tal principio postula que la publicidad deberá efectuarse en idioma español y en términos comprensibles, exigiendo el uso de citas aclaratorias para entregar información adicional sobre una palabra o concepto -no para modificar sustancialmente el mensaje publicitario-y admitiendo textos en letra chica para proporcionar información adicional o sobre materias que por su extensión o importancia no merecen destacarse con igual énfasis que

${ }^{36}$ Baquero Herrera, Mauricio y Caballero Germain, Guillermo. Artículo $17 G$ en De la Maza, Iñigo- y Pizarro, Carlos (dirs.), Barrientos, Francisca (coord.), La Protección de los Derechos de los Consumidores. Comentario a la Ley de Protección a los derechos de los consumidores (Santiago, Editorial Thomson Reuters, 2013), p. 461.

${ }^{37}$ Sobre el alcance de este precepto véase EsPada Mallorquín, Susana, Artículo $3 F$, en De la Maza, Iñigo- y Pizarro, Carlos (dirs.), Barrientos, Francisca (coord.), La Protección de los Derechos de los Consumidores. Comentario a la Ley de Protección a los derechos de los consumidores (Santiago, Editorial Thomson Reuters, 2013), pp. 133-139 e Isler, Erika. Derecho del consumo ..., cit. (n.22) ), pp. 228-235. 
los textos principales, en la medida que tengan un tamaño y disposición que permitan su fácil lectura y comprensión ${ }^{38}$.

Con todo, las exigencias contenidas en el artículo 17G, y la transparencia de la información publicitaria que de él se deriva, han sido desestimadas con cierta frecuencia por los proveedores financieros, como lo revelan algunos Estudios al Mercado Financiero efectuados por el SERNAC. Sirva de ejemplo el "Estudio Publicidad Mercado Financiero Origen Regional-Región del Maule" de octubre de 2015 ${ }^{39}$, que analizó la publicidad realizada a través de insertos en prensa escrita, en oficinas y locales comerciales, volantes que se entregan a los consumidores y aquella que se efectúa en la vía pública a través de gigantografías que consignó, entre sus principales observaciones, la entrega de información adicional del crédito en forma vertical y con un tamaño que imposibilita su lectura, la ilegibilidad del tiempo de validez de la oferta y de las condiciones para acceder al crédito y el no otorgamiento a la publicidad de la CAE de un tratamiento similar al de la publicidad de la cuota o tasa de interés de referencia.

De otro lado, ha sido objeto de diversos litigios en los últimos años, asentándose que forma parte de su supuesto de hecho que la publicidad verse sobre una operación de crédito de dinero y que ella emane de un proveedor de servicios financieros. Así, nuestros tribunales han descartado la aplicación del artículo $17 \mathrm{G}$ y la exigencia de informar la tasa de interés de referencia, la CAE y el CTC (costo total del crédito) tratándose de la publicidad de paquetes turísticos en que se inserte información sobre uso de tarjetas Transbank, expresando, de un lado, que ello da cuenta de la modalidad de pago pero no constituye publicidad de una operación crediticia ni de servicios de crédito o de tarjetas de crédito y, de otro, que la denunciada no ofreció en su publicidad créditos de consumo, no impuso un recargo por pago de cuotas ni ostenta la calidad de prestadora de servicios financieros, requisitos todos ellos indispensables para la procedencia de dicho precepto ${ }^{40}$.

${ }^{38}$ López, Patricia, La publicidad comercial..., cit. (n. 3), pp. 35-37.

${ }^{39}$ Disponible en https://www.sernac.cl/portal/619/articles-4448_archivo_01. pdf. [fecha de consulta: 14 de septiembre de 2020].

${ }^{40}$ En Segundo Juzgado de Policía Local de Las Condes, "SERNAC con Travel Security S.A”, 25 de junio de 2014, Rol 23048-5/2014, Segundo Juzgado de Policía Local de Las Condes, "Sernac con Lan Tours División de Servicios Terrestres S.A.", 9 de marzo de 2015, Rol 23049-10/2014, Primer Juzgado de Policía Local de Las Condes, "SERNAC con Turismo Cocha S.A.", 7 de agosto de 2015, Rol 1899-8/2015, Segundo Juzgado de Policía Local de Providencia, "SERNAC con Distribuidora de Industrias Nacionales S.A.”, 7 de agosto de 2015, Rol 5380F/2015, Segundo Juzgado de Policía Local de Las Condes "Sernac con Cencosud 
Asimismo, se ha admitido su aplicación en aquellos casos en que la omisión de la información versa sobre la CAE, el CTC y el tiempo o plazo de vigencia de la promoción en medios de comunicación masivos, toda vez que dichos anuncios llegan a consumidores que no tienen suficientes conocimientos financieros o contables, lo que determina que puedan tener una impresión errónea respecto del costo final del crédito, propiciando la publicidad engañosa y la falta de información veraz y oportuna. Así aconteció en SERNAC con Banco de Chile en que se estimó que la publicidad radial del producto financiero "Tarjeta de Crédito Travel" incumplía normas de información y publicidad, dado que una voz en off expresaba lo siguiente: “¡Oh! Te queda increíble... me encanta ese color... es que el diseño... se pasó ¿¡Y viste? A mitad de precio y en 12 cuotas. Cámbiate en marzo a Banco Edwards-City, pagando con tus nuevas tarjetas travel, llévate a mitad de precio y en 12 cuotas sin interés un Ipad Air Wifi de 16 Gigabytes" ${ }^{\prime 1}$. Otro tanto ocurrió en SERNAC con Klassik Car S.A. en que la denunciada difundió publicidad de ciertos modelos de automóviles en el diario La Tercera, informando un precio a crédito inferior al precio de la lista acompañado de una letra chica en que se indicaba "Precio válido con financiamiento Forum, con pie máximo de 5\% y un plazo mínimo de 24036 cuotas. Aprobación sujeta a confirmación de antecedentes financieros y comerciales del cliente. Precios disponibles hasta agotar stock. Fotos referenciales" ${ }^{\prime 2}$.

Reclamos similares han suscitado el pronunciamiento de oficio del Consejo de Autorregulación y Ética Publicitaria (CONAR) por infracción de los artículos 8 y 16 del CchEP referentes a la veracidad y engaño y a la publicidad de precios, como lo revela el Dictamen Ético pronunciado el 15 de abril de 2020 en contra de la publicidad gráfica en prensa escrita de un automóvil perteneciente a Nissan Chile SpA. El problema fue que dicha

Retail S.A. y Cencosud Administradora de Tarjetas S.A.”, 23 de marzo de 2015, Rol 42109-5/2014. En otros casos, los tribunales de primera instancia que tuvieron que conocer del asunto no efectuaron un análisis de la infracción denunciada por allanarse la reclamada, teniendo por configurada la vulneración del artículo 17G (véase Segundo Juzgado de Policía Local de Las Condes, "SERNAC con Mitsui Auto Finance Chile Limitada”, 15 de noviembre de 2017, Rol 47088-5/2017 y Segundo Juzgado de Policía Local de Las Condes "SERNAC con Importadora DESMO Limitada y Tanner Servicios Financieros S.A.”, 13 de marzo de 2018, Rol 5505710/2017).

${ }^{41}$ Considerando tercero de la sentencia del Cuarto Juzgado de Policía Local de Santiago, "SERNAC con Banco de Chile", 30 de marzo de 2016, Rol 14114-5/2015.

${ }^{42}$ Considerando noveno de la sentencia pronunciada por el Primer Juzgado Civil de Vitacura, "SERNAC con Klassik Car S.A.", 19 de noviembre de 2014, Rol 410359-8/2014. 
empresa publicitó en el diario la Tercera y en el Mercurio el modelo Qashqai Sense MT bajo el título "Nissan REDSALE”, destacando la fotografía del vehículo sobre un fondo rojo que señalaba " $0 \%$ interés", indicando más abajo "Desde $\$ 11.990 .000$ Bono credi Nissan plus $\$ 3.221 .000$ ” y "CAE: 6,87\%/Precio Lista \$15.211.000/CTC \$6.433.576" e insertando una cita aclaratoria con las condiciones y costo del crédito para la compra a 24 meses, modificando así sustancialmente el mensaje principal de la pieza e induciendo a error al público respecto del precio al cual es posible obtener el producto publicitado. En atención a tales hechos el CONAR acogió el reclamo, expresando en los considerandos octavo y noveno lo siguiente:

"Que, al señalarse de manera destacada en el aviso que el valor anunciado para el vehículo publicitado no está sujeto a interés, es de esperar que el público entienda con esa declaración absoluta que dicho valor no está asociado a un crédito que por su propia naturaleza, y casi en la totalidad de los casos, está justamente sujeto a interés. En efecto, cuando se habla de que un determinado valor total no está sujeto a interés, se entiende que el precio total no está sujeto al pago de un valor adicional condicionado a la forma de pago. En el caso en cuestión, al agregarse detalles sobre las condiciones de la aplicación, como que el $0 \%$ de interés corresponde a un 50\% del valor del vehículo, se relativiza la oferta principal y se genera confusión al enfrentarse a la publicidad.

(...) si a lo anterior se agrega que el nivel de comprensión del público promedio en aspectos financieros no es muy alto en general, lo que incluso ha dado lugar a iniciativas legales para regular estos aspectos como aquella que se refiere al CAE, se espera que en las piezas en que se trate este tipo de temas, especialmente tratándose de productos que suelen comprarse con crédito como los automóviles, el avisador sea lo más claro posible, no limitándose sólo a cumplir con la ley sino con las normas éticas que rigen en materia publicitaria para evitar confusiones y promover la confianza del público en la publicidad" ${ }^{43}$.

Una preocupación más evidente respecto del contenido de la publicidad comercial y de la necesidad que esta se sujete a determinados principios se advierte en los Reglamentos destinados a regular la publicidad dirigida al consumidor financiero. En efecto, todos ellos contienen, además de una noción de publicidad como lo apuntamos al referirnos a ella en el apartado precedente, un título denominado "Información publicitaria" cuyos artículos reproducen algunas disposiciones de la LPC al tipificar la

${ }^{43}$ CONAR, "De oficio con Nissan Chile SpA", 15 de abril de 2002, Rol 1137/2020, disponible en https://www.conar.cl/wp-content/uploads/2020/04/Rol1137-Fallo-Conar.pdf. [fecha de consulta: 14 de septiembre de 2020]. 
información publicitaria mínima, regular la publicidad que se realiza por correo electrónico y otros medios tecnológicos y consagrar explícitamente el principio de veracidad publicitaria e implícitamente el principio de transparencia publicitaria ${ }^{44}$.

Así, bajo el epígrafe "Información publicitaria mínima” los artículos 33, 35 y 34 de los Reglamentos sobre Información de Crédito Hipotecario, de Crédito de Consumo y de Tarjetas de Crédito reproducen, respectivamente, la primera parte del artículo $17 \mathrm{G}$ de la LPC, aunque incompletamente. $\mathrm{Y}$ es que ellos prescriben que los proveedores deberán informar la CAE en toda publicidad de créditos hipotecarios, créditos de consumo y tarjetas de crédito en que se informe una cuota o tasa de interés de la referencia y que se realice a través de cualquier medio masivo o individual, precisando que deberán otorgar a la publicidad de la CAE un tratamiento similar al de la CAE o cuota de interés de referencia, sin aludir a la "tipografía de la gráfica, extensión, ubicación, dicción, repeticiones y nivel de audición”, como lo hace aquel precepto. Se trata, como lo precisamos más arriba, de una manifestación del principio de transparencia publicitaria que, en parte, reitera lo dispuesto en el inciso 1 del artículo 32 de la LPC a propósito de la información básica comercial, toda vez que dispone, en lo que aquí interesa, que dicha publicidad deberá efectuarse en "idioma castellano, en términos comprensibles y legibles, en moneda de curso legal, sin perjuicio que el proveedor pueda incluir, adicionalmente, esos mismos datos en otro idioma o unidad monetaria", extendiendo tal exigencia a aquella que se realice en sitios de internet.

De otro lado, tales Reglamentos reproducen lo preceptuado en el artículo 28 B de la LPC al disciplinar las comunicaciones publicitarias enviadas por correos electrónicos, correo postal, fax, llamados o servicios de mensajería telefónicos, prescribiendo sus artículos de 32, 34 y 33 que deberá indicarse expresamente que se refiere a un crédito hipotecario, a un crédito de consumo o a una tarjeta de crédito, según el caso, la identidad del remitente y una dirección válida a la que el destinatario pueda solicitar la suspensión de tales envíos. Precisan además que la información remitida con posterioridad, pese a la solicitud de suspensión, se regirá por lo dispuesto en dicho precepto, advirtiéndose una manifestación del principio de legalidad publicitaria cuya infracción, en este

${ }^{44} \mathrm{Y}$ que corresponden a los artículos 34 a 37 del Reglamento sobre información de Créditos Hipotecarios, artículos 32 a 35 del Reglamento sobre Información de Créditos de Consumo y a los artículos 33 a 36 del Reglamento de Información sobre Tarjetas de Crédito bancarias y no bancarias. 
supuesto, configura una hipótesis de publicidad agresiva por acoso ${ }^{45}$, que examinaremos en el próximo aparatado.

Finalmente, los referidos Reglamentos exigen expresamente en sus respectivos artículos 37,35 y 36 veracidad en la información, señalando que toda información que se consigne en la publicidad y difusión del crédito hipotecario, del crédito de consumo y de la tarjeta de crédito “deberá ser veraz, esto es, susceptible de comprobación, y no podrá contener expresiones que induzcan a error, engaño o confusión al consumidor”. Tal premisa la recoge la LPC en los artículos 28 y 33 a propósito de la publicidad en general y tratándose del consumidor financiero en el artículo 17L y se ha elevado a la categoría de principio publicitario no sólo a nivel dogmático sino también administrativo, como lo revela la ya aludida CIPP del SERNAC ${ }^{46}$. En efecto, ella equivale al denominado principio de veracidad publicitaria según el cual las afirmaciones contenidas en los anuncios publicitarios deben ser veraces y tener siempre el mismo significado o interpretación, de modo que no pueden inducir a error o confusión a los consumidores respecto de los hechos que el mensaje comunica, excluyéndose, por consiguiente, los anuncios constituidos por frases triviales o carentes de contenido, los juicios estimativos o valorativos del anunciante y las exageraciones publicitarias. ${ }^{47}$

Toda esta regulación de la publicidad comercial que hemos referido propende, como se advierte, a un sistema de corresponsabilidad, dado que exige al proveedor financiero proporcionar información detallada del producto o servicio a través de ella. Pero lo cierto es que para alcanzar una

${ }^{45}$ Dado que la vulneración de este principio también puede determinar la existencia de publicidad abusiva. Sobre esta especie de publicidad ilícita véase LóPEZ Díaz, Patricia Verónica. La publicidad abusiva y agresiva: un intento de configuración dogmática en el derecho chileno y la tutela de los consumidores frente a tales prácticas comerciales, en VÁsquez Palma, María Fernanda (dir.) Estudios de Derecho Comercial, $X$ Jornadas Nacionales de Derecho Comercial (Valencia, Editorial Tirant lo Blanch, 2020), pp. 218-222, 225-228 y 232-233 y López, Patricia, La publicidad abusiva..., cit. (n. 13).

${ }^{46}$ CIPP, cit. (n. 4), p. 9.

${ }^{47}$ Sobre este tópico véase Fernández Fredes, Francisco. Manual de Derecho Chileno de Protección del Consumidor (Santiago, Lexis Nexis, 2003), p. 54 y López, Patricia, La publicidad comercial..., cit. (n. 3), pp. 32 y 33. La LPC no alude directamente a este principio, pero exige, en diferentes preceptos referidos a la publicidad, que la información que se proporcione al consumidor sea veraz y unívoca, lo que permite sostener que ella lo recoge. Tal es el caso del artículo 3 letra b) que consagra el derecho del consumidor a una información veraz y oportuna y de los artículos 28, 28A, 17L y 33 relativos a la publicidad engañosa que han servido para erigir, junto a muchos otros, el principio protector y el de confianza razonable que repudian la inducción a error o engaño a través del mensaje publicitario. 
tutela más efectiva del consumidor financiero debería exigírsele, además de la observancia de los deberes de consejo y de adecuación ${ }^{48}$, efectuar las advertencias que resulten pertinentes en la publicidad, dado que el exceso de información que debe proporcionársele unido al tecnicismo de ella, genera una paradoja regulatoria que conduce a su desprotección y lo hacen más susceptible a incurrir en engaño, error o confusión. Y es que si bien el deber de advertencia no está contenido en la normativa analizada, este puede construirse dogmáticamente a partir de la buena fe y del deber de colaboración que ella impone en la fase precontractual, así como de la analogía integradora de ciertos artículos contenidos en el Código Civil ${ }^{49}$, de modo que no existiría inconveniente para exigirlo. Más aún si tratándose de la vulneración del artículo 17L se ha reprochado al anunciante no haber advertido al consumidor financiero el alcance de la publicidad, como examinaremos en el próximo apartado ${ }^{50}$.

\section{Normas relativas a la publicidad ilícita dirigida al consumidor finan-} ciero: la regulación de la publicidad engañosa y el repudio de la publicidad agresiva

A las normas generales sobre publicidad de servicios y productos financieros señaladas precedentemente se añaden otras que no sólo constituyen una manifestación del principio de veracidad sino también del principio de legalidad publicitaria, advirtiéndose dos especies de publicidad ilícita respecto del consumidor financiero que han concitado el interés de nuestro legislador explícita o implícitamente: la publicidad engañosa y la publicidad agresiva.

Tal preocupación se explica, en parte, por el carácter hipervuln erable del consumidor financiero al que ya hemos aludido y porque, como se ha consignado en el punto 27 de la Resolución del Parlamento Europeo de 22 de Mayo de 2012 sobre una Estrategia de Refuerzo de los Derechos de los Consumidores, las explicaciones que se ofrecen en la publicidad de productos y servicios de inversión financiera sobre los

${ }^{48}$ GoldenberG, Juan, El sobreendeudamiento y los paradigmas..., cit. (n.10), pp. 14-20. Sobre el alcance de tales deberes véase GolDENBERG, Juan Luis. Los contornos del deber de consejo..., cit. (n. 8), pp. 9-41 y López, Patricia ¿Es la obligación/deber de advertencia una categoría exclusiva ..., cit, (n. 8), pp. 929-958.

${ }^{49}$ En tal sentido véase SAN Martín Neira, Lilian, El "deber de aviso" ante la ocurrencia de un caso fortuito o fuerza mayor ¿tiene aplicación en Chile? en ELORRIAGA, Fabián (coord.), Estudios de Derecho Civil VII (Santiago, AbeledoPerrot Thomson Reuters, 2012), pp. 547- 560 y LOPEZ, Patricia ¿Es la obligación/deber de advertencia una categoría exclusiva..., cit, (n. 8), pp. 946-953.

${ }^{50}$ Corte de Apelaciones de Antofagasta, "Álvarez con Falabella", 16 de junio de 2016, Rol119-2016. 
riesgos subyacentes son a menudo insuficientes y focalizan la atención en beneficios potenciales que no suelen materializarse, exponiendo a tales consumidores al riesgo de perder su capital, resultando indispensable la incorporación de normas más estrictas que regulen dicha publicidad.

Pues bien, habida consideración de que la publicidad ilícita es aquella que contraviene los principios sobre los cuales debe erigirse así como los derechos de los consumidores ${ }^{51}$, se hace necesario regular sus distintas especies con el propósito de tutelar el derecho a la libre elección del bien o servicio del consumidor, el derecho a una información veraz y oportuna y el derecho a la seguridad en el consumo signados en los literales a), b) y d) del artículo 3 de la LPC. Claro está que nuestro legislador no ha emprendido tal desafío en una ley general ni especial, pero lo ha abordado parcialmente a propósito del consumidor financiero tratándose de los dos primeros derechos que hemos referido, como lo constataremos en las líneas que siguen ${ }^{52}$.

a) La publicidad engañosa: un ilícito expresamente disciplinado en el artículo 17 L de la LPC. Como se sabe, el propósito de la Ley 20.555 fue otorgar una protección más efectiva al consumidor financiero a través de la incorporación de diversos literales al artículo 17 de la LPC -cuyo objetivo es regular la información que debe proveérseles, así como proscribir las ventas atadas y los envíos no solicitados-; y del artículo 62 que exige dictar Reglamentos que regulen la publicidad dirigida al consumidor financiero. Tal finalidad es la que explicaría que el literal L del artículo 17 discipline la publicidad engañosa a propósito de este consumidor en una norma especialmente destinada al efecto en los siguientes términos:

"Los proveedores de servicios o productos financieros que entreguen la información que se exige en esta ley de manera que induzca a error al consumidor o mediante publicidad engañosa, sin la cual no se hubiere contratado el servicio o producto, serán sancionados con las multas previstas en

${ }^{51}$ Tales son los principios de legalidad publicitaria, veracidad, autenticidad o identificación publicitaria, comprobabilidad, integración publicitaria, transparencia, disponibilidad y acceso a la información, respeto a la competencia y autosuficiencia del soporte publicitario. Véase CIPP, cit. (n. 4), pp. 9-11 y LOPEZ, Patricia, La publicidad comercial..., cit. (n. 3), pp. 28-36.

${ }^{52}$ En efecto, no se advierte un interés por disciplinar la publicidad abusiva con el propósito de evitar la vulneración del derecho a la seguridad en el consumo signado en la letra d) del artículo 3 de la LPC, entendiendo que esta comprende la salud y, a la vez, la integridad física y síquica. Sobre esta especie de publicidad véase LOPEz, Patricia, La publicidad abusiva..., cit. (n. 13). 
el artículo 24 en sus respectivos casos, sin perjuicio de las indemnizaciones que pueda determinar el juez competente de acuerdo a la presente ley".

Sin embargo, dicho precepto no alcanza el objetivo que persigue, porque la técnica legislativa empleada es defectuosa, al menos en tres aspectos. En primer lugar, porque distingue la inducción a error de la publicidad engañosa, en circunstancias que aquella se subsume en esta última, deviniendo en una forma de engaño. En segundo lugar, no introduce ninguna particularidad propia de la contratación de productos y servicios financieros a través de una fórmula general o particular como acontece en los Reglamentos sobre información de Créditos Hipotecarios, Crédito de Consumo y Tarjetas de Crédito que refieren condiciones objetivas sobre las que dicha publicidad puede recaer y que examinaremos más adelante. Finalmente, se desapega inútil y confusamente del inciso primero del artículo 28 de la LPC que establece el supuesto de hecho de la publicidad engañosa al precisar que comete infracción a las disposiciones de esta ley "el que, a sabiendas o debiendo saberlo y a través de cualquier tipo de mensaje publicitario induce a error o engaño" respecto de alguna de las condiciones objetivas que dicho precepto señala.

Esta falta de concordancia ha concitado la crítica de nuestra doctrina que ha calificado al artículo $17 \mathrm{~L}$ como irreflexivo, reiterativo e innecesario ${ }^{53}$ y ha determinado el surgimiento de cuatro interrogantes: i) ¿Cuándo se aplica dicho precepto por sobre el artículo 28? ii) ¿ el artículo 17L sólo tiene cabida respecto de los actos de publicidad engañosa cometidos con dolo? y iii) ¿Qué características debe cumplir la "inducción a error o a engaño" para que proceda este artículo? iv) ¿cuáles son las sanciones por infringir el artículo $17 \mathrm{~L}$ ?54.

El problema es que ellas han sido respondidas exigiendo la culpa o dolo del anunciante para que exista publicidad engañosa, distinguiéndola de la publicidad falsa, restringiendo en demasía su noción y los mecanismos de tutela que se activan respecto del consumidor financiero frente a su acaecimiento. Así, en lo que concierne a la primera interrogante, se ha sostenido que el supuesto de hecho de dicho precepto se configura, en lo que aquí interesa, cuando los proveedores de servicios y productos financieros realicen actos de publicidad engañosa, entendiendo por tales tarjetas de crédito y de débito, cuentas corrientes, cuentas vistas y líneas

${ }^{53}$ De la MAZA, Iñigo. La ley 20.555: oportunidad y pulcritud, en Análisis Jurídico, Mercurio Legal, 9 de julio de 2012, disponible en https://www.elmercurio. com/Legal/Noticias/Analisis-Juridico/2012/07/09/La-ley-20555-oportunidady--pulcritud.aspx. [fecha de consulta: 16 de septiembre de 2020] y FernándeZ, Fernando, cit. (n. 12), pp. 505-506.

${ }^{54}$ Fernández, Fernando, cit. (n. 12), pp. 507-512. 
de créditos, cuentas de ahorro, créditos hipotecarios, créditos de consumo, contratos colectivos de seguro de desgravamen, cesantía, incendio y sismo, asociados a los productos y servicios financieros y otros que tengan características similares. Tratándose de la segunda se ha aseverado que, a pesar que el artículo $17 \mathrm{~L}$ no sanciona al proveedor que ha obrado "a sabiendas" de que induce a error o engaño al consumidor o "debiendo saberlo", el espíritu de la Ley 20.555 no permite concluir que deba otorgársele una lectura restrictiva que descarte los actos negligentes, comprendiendo así a estos últimos y a los dolosos, equiparándose por vía interpretativa a la literalidad del artículo 28. En lo que respecta a la tercera, esto es, a las características de la inducción o engaño se ha sostenido que ella debe haber sido determinante para que el consumidor financiero contrate, atendida la expresión "sin la cual no se hubiere contratado el servicio o producto", debiendo este último acreditar tal circunstancia. Por último, a propósito de las sanciones derivadas de su infracción, se ha establecido que estas comprenden la multa infraccional del artículo 24 de la LPC -que puede llegar hasta las 1.500 UTM o 2.250 UTM, según el caso- y las indemnizaciones que resulten pertinentes.

Lo cierto es que una interpretación armónica de todos los preceptos que regulan la publicidad engañosa en la LPC- esto es del artículo 17L junto a los artículos $28,28 \mathrm{~A}$ y $33-$, nos puede conducir a la conclusión que se trata de una categoría de publicidad ilícita que se configura con la sola "posibilidad o aptitud del mensaje publicitario para inducir a error o engaño al consumidor", sin que se relevante la culpa o dolo del proveedor ${ }^{55}$.

Esta constatación nos permite responder las interrogantes formuladas con antelación en forma más simple y constatar que el ilícito publicitario contenido en los artículos 28 y $17 \mathrm{~L}$ es el mismo y que sólo difieren en el contenido sobre el que recae la inducción a error o engaño, más no en la imputabilidad del anunciante ni en el carácter determinante de tal inducción. Así, en lo que concierne a la primera pregunta relativa a la primacía del artículo $17 \mathrm{~L}$ respecto del artículo 28 , la respuesta es que el supuesto de hecho disciplinado en el primero varía en cuanto al agente de la publicidad y las condiciones objetivas sobre las cuales ella puede recaer en atención a que la información es más técnica y específica pero, al igual que aquel contenido en el artículo 28, se configura por la sola virtualidad, potencialidad o aptitud de inducir a error o engaño al consu-

55 De la Maza, Iñigo, Artículo 28, cit. (n. 2), pp. 660-661, Barrientos, Francisca, cit. (n. 2), pp. 67-69, De la Maza Gazmuri, Iñigo. Publicidad engañosa: noción amplia y consecuencias, ponencia presentada en las IX Jornadas Nacionales de Derecho de Consumo, organizadas por la Universidad Arturo Prat, Iquique, 2019 y López, Patricia, La tutela de la publicidad engañosa..., cit. (n. 2), pp. 843 y 844 
midor. Por consiguiente, la respuesta a la segunda interrogante sería que lo determinan te para que exista la publicidad engañosa es precisamente esta circunstancia y no la culpa o dolo del anunciante. De otro lado, las características de la inducción a error o engaño de la publicidad del artículo $17 \mathrm{~L}$ son las mismas que las del artículo 28 , aunque este último no contenga la frase "sin la cual no se hubiere contratado el servicio o producto", toda vez que basta la potencialidad del mensaje publicitario para generar tal inducción. Finalmente, en lo que refiere a las consecuencias derivadas de dicha publicidad, además de la multa infraccional y de la indemnización de daños, cabría agregar la suspensión publicitaria, la publicidad correctiva y la integración publicitaria expresamente previstas en los artículos 31 -las dos primeras- y en el artículo $1 \mathrm{~N}^{\circ} 4$ y 28 de la LPC la última, toda vez que la publicidad engañosa comprende a la falsa, dado que ella también tiene la virtualidad de inducir a error o engaño ${ }^{56}$.

Nuestros tribunales, por su parte, no han tenido muchas oportunidades para pronunciarse respecto de la vulneración del artículo 17L. En efecto, sólo existiría un caso en que se ha reclamado su infracción ${ }^{57}$. Se trata de Álvarez con Falabella de 2016 en que se dedujo denuncia infraccional y demanda indemnizatoria, pues la recurrente concurrió a la tienda "Nacional" a comprar ropa de colegio que pagó con su tarjeta CMR Falabella, porque días antes había recibido una oferta contenida en una publicidad gráfica que indicaba "aprovecha esta vuelta a clases con un $20 \%$ en todos los productos, incluyendo textos escolares. Exclusivo con CMRVISA, CMR FALABELLA y BANCO FALABELLA”. En tal

\footnotetext{
${ }^{56}$ De hecho la historia fidedigna del establecimiento de la LPC revela que ambas expresiones se utilizaron como sinónimas. Disponible en https://www.bcn.cl/ historiadelaley/nc/historia-de-la-ley/6746/. En igual sentido FERnÁNDEZ, Francisco, cit. (n. 44), p. 56 e Isler Soto, Erika. Artículo 31, en De la Maza, Iñigo- y Pizarro, Carlos (dirs.), Barrientos, Francisca (coord.), La Protección de los Derechos de los Consumidores. Comentario a la Ley de Protección a los derechos de los consumidores (Santiago, Editorial Thomson Reuters, 2013), p. 724.

${ }^{57}$ Pues ilicitudes publicitarias que podrían haberse reconducido también al artículo $17 \mathrm{~L}$ de la LPC se han encausado a través del artículo $28 \mathrm{~A}$ de dicha Ley. Así aconteció en "Servicio Nacional del Consumidor con Banco Consorcio" y en "Servicio Nacional del Consumidor con Banco Créditos". En el primero el referido banco utilizó sin autorización el logo "SERNAC FINANCIERO" en su página web induciendo a que el consumidor interesado en tal servicio contratara amparado en que dicha institución se encontraba respaldada por el SERNAC, sin que dicho sello estuviera operativo. En el segundo, el denunciado se publicitó como banco, omitiendo informar al público que no era proveedor financiero y que no se encontraba registrado como tal en el Registro de Superintendencia de Bancos e Instituciones Financieras. Véanse, respectivamente, Corte de Apelaciones de Santiago, 15 de enero de 2014 y Juzgado de Policía Local de Las Condes, 27 de junio de 2017.
} 
convencimiento acudió a la caja y al hacer exigible la oferta se le indicó que podía utilizarlo una vez y que la promoción era válida sólo para Santiago, cuestión que no constaba en el folleto publicitario. El Juzgado de Policía Local desestimó la querella y la demanda ante lo cual el SERNAC dedujo recurso de apelación ante la Corte de Apelaciones de Antofagasta que fue acogido, estimando dicho tribunal que efectivamente se vulneró el artículo 17L y condenado a Falabella al pago de una multa de 25 UTM y a la indemnización del daño emergente y daño moral a la consumidora. En tal sentido precisó lo siguiente:

"La inducción a error se inicia con el envío de una propaganda a regiones sobre compras de productos con rebaja que debe realizarse en Santiago, sin que se realice adverten cia alguna, lo que colabora al error; todo lo cual significa alterar una información con el objeto de inducir al cliente a una compra, sin precisar que la promoción es restringida solo a la tienda Nacional, más aún si la propia propaganda también es engañosa cuando muestra cuatro logos de similares tamaños ubicados al centro de la propaganda sin restricción alguna, refiriéndose que el descuento se realiza al momento de pagar exclusivamente con CMR Visa, CMR Falabella y Banco Falabella. No se advierte en forma clara que se trata de una propaganda de beneficio exclusivamente para una tienda distinta a Falabella Retail S.A., por lo que habiéndose incurrido en publicidad engañosa que induce a error, es decir, abarcando ambos aspectos de protección al consumidor, no cabe sino aplicar la multa que ordena el artículo 17L de la Ley 19.496 en los montos fijados en el artículo 24 de este mismo cuerpo legal"58.

Finalmente, en lo que respecta a este ilícito publicitario, cabe consignar que la regulación reglamentaria de la publicidad engañosa resulta más acabada que la contenida en el artículo 17L, pues los Reglamentos sobre Información de Créditos Hipotecarios, de Créditos de Consumo y de Tarjetas de Crédito si bien no la definen, atendido su particular objeto de regulación, incorporan condiciones objetivas fin a ncie ras que se pueden incluir en la publicidad y, por consiguiente, integrar al contrato con el propósito de tutelar más acabadamente al consumidor financiero, distintas a aquellas previstas en el artículo 28 de la LPC. En efecto, el primero de ellos agrega catorce condiciones objetivas en su artículo $3 \mathrm{~N}^{\circ} 38^{59}$, el

\footnotetext{
${ }^{58}$ Véase considerando quinto, Corte de Apelaciones de Antofagasta, "Álvarez con Falabella”, 16 de junio de 2016, Rol119-2016. El destacado es nuestro.

${ }^{59}$ Tales son: a) Modalidad del Crédito Hipotecario; b) Monto Líquido del Crédito Hipotecario; c) Monto Bruto del Crédito Hipotecario; d) Tasa de Interés Anualizada; e) Valor del Dividendo; f) Plazo del Crédito Hipotecario; g) Gastos Asociados al Otorgamiento del Crédito Hipotecario; h) Seguros Asociados al Crédito Hipotecario; i) Costo Total del Crédito Hipotecario; j) Carga Anual Equivalente; k)
} 
segundo Reglamento añade trece en su artículo $3 \mathrm{~N}^{\circ} 40^{60}$ y tercero señala nueve en el artículo $3 \mathrm{~N}^{\circ} 56^{61}$, destacando como condiciones comunes la CAE, el interés moratorio y el gasto de cobranza, evidenciando la especial preocupación por tutelarlo que hemos venido comentando.

b) La publicidad agresiva: un ilícito publicitario que puede construirse a partir del artículo $17 \mathrm{~F}$ y $17 \mathrm{H}$ de la LPC.- Hasta acá hemos revisado una especie de publicidad ilícita expresamente reglada respecto del consumidor financiero. Pero existe otra no regulada denominada publicidad agresiva cuyo repudio respecto del consumidor en general y del consumidor financiero, que es el que aquí interesa, puede advertirse, a nuestro juicio, a partir de ciertas disposiciones contenidas en la LPC.

Esta categoría publicitaria, concebida como un acto de competencia desleal en el derecho europeo ${ }^{62}$, es aquella que a través de la coacción, acoso e influencia indebida vulnera la libertad de elección de los consumidores, limitando significativamente su capacidad para adoptar una decisión económica ${ }^{63}$. Existe coacción si a través de fuerza la física o de otra clase se ocasiona un daño a un consumidor o se amenaza con ocasionarlo, generando en éste la expectativa que tal celebración acarreará el cese de dicha amenaza o la obtención de un beneficio real. El acoso, en cambio, se verifica si a través de la publicidad se presiona al potencial adquirente de un producto para comprarlo directamente o a distancia, impidiéndole

Comisión por Pago Anticipado o Prepago; l) Costo Total del Pago Anticipado o Prepago; m) Interés Moratorio; y n) Gasto de Cobranza.

${ }^{60}$ Estas son: a) Monto Líquido del Crédito; b) Monto Bruto del Crédito; c) Tasa de Interés Anualizada; d) Valor de la Cuota; e) Valor de la Cuota Básica de Referencia; f) Plazo del Crédito; g) Gastos o Cargos Propios del Crédito; h) Costo Total del Crédito; i) Carga Anual Equivalente; j) Comisión por Pago Anticipado o Prepago; k) Costo Total del Pago Anticipado o Prepago; l) Interés Moratorio; y m) Gasto de Cobranza.

${ }^{61}$ Dichas condiciones son: a) Cupo Total; b) Cupo Total para Compras en Cuotas; c) Cupo Total para Avances en Efectivo; d) Plazo de Vigencia del contrato de apertura de línea de crédito para la utilización de una Tarjeta de Crédito; e) Costos de Apertura, Comisiones y Cargos de la Tarjeta de Crédito; f) Costos de Administración, Operación y/o Mantención de la Tarjeta de Crédito; g) Carga Anual Equivalente; h) Interés Moratorio; y i) Gastos de Cobranza.

${ }^{62}$ Véase Aguilar, Yolanda, cit. (n. 15), pp. 116-146 y GonZÁlez Pons, Elisabet. Prácticas agresivas y tutela del consumidor (Madrid, Boletín Oficial del Estado, 2019).

${ }^{63}$ Sobre tal noción véase MASSAGUER, José. Las prácticas agresivas como actos de competencia desleal, Revista Actualidad Jurídica Uría Méndez 27 (2010), pp. 27 y 28, Vilajoana, Sandra Alejandre. Las Leyes de la publicidad. Limites jurídicos de la actividad publicitaria (Barcelona, Editorial Universitat Oberta de Catalunya, 2011), pp. 96-105 y, más detenidamente, AgulLar, Yolanda, cit. (n. 15), pp. 106-113. 
que reflexione sobre la conveniencia de tal transacción. Es lo que sucede si se realizan frecuentes visitas a su domicilio en las que se desestima la petición de abandonar el lugar o de no volver o se efectúan propuestas no deseadas y reiteradas por teléfono, fax, correo electrónico u otros medios de comunicación. Finalmente, la influencia in debida tiene lugar cuando el anunciante se aprovecha de la posición de poder que ostenta respecto del destinatario de la publicidad, disminuyendo significativamente su capacidad para adoptar una decisión económica ${ }^{64}$. Se presenta, en lo que a aquí interesa, si existe una relación entre un experto y un consumidor que precisa sus servicios, como acontece si este publicita un producto contrario a los intereses del consumidor necesitado de financiamiento, o si interviene un influenciador, toda vez que este desvía deliberadamente los gustos del consumidor a los intereses económicos de la marca que publicita.

La publicidad agresiva constituye una infracción al principio de legalidad publicitaria, esto es, a aquel según el cual la publicidad debe abstenerse de incluir expresiones, imágenes o insinuaciones que ofendan valores fundamentales vinculados a la dignidad, libertad e igualdad esenciales de las personas, siendo su referente más inmediato en el derecho de consumo el principio de protección del consumidor ${ }^{65}$. De allí que este principio publicitario pueda construirse no sólo a partir de la tutela de las garantías constitucionales sino del artículo 3 letra c) de la LPC según el cual el proveedor no puede ser discriminado arbitrariamente por los proveedores de bienes y servicios ${ }^{66}$, agregándose el literal d) de dicho precepto que consagra el derecho de la seguridad en el consumo que comprende el derecho a la salud y a la integridad física y síquica del consumidor.

Esta especie de publicidad ilícita no se encuentra regulada en nuestro ordenamiento jurídico, pero como lo ha asentado nuestra dogmática existen, de un lado, normas que se explican en razón de ella y, de otro, preceptos a partir de los cuales puede sustentarse su procedencia respecto del consumidor en general. En el primer grupo se encuentra el artículo 3 bis a) que disciplina el derecho a retracto del consumidor tratándose de

${ }^{64}$ A propósito de todas estas especies de publicidad agresiva véase Massaguer, José, cit. (n. 63), p. 27-28, Vilajoana, Sandra, cit. (n. 63), pp. 100-103 y MartíneZ escribano, Celia, Herrero Suárez, Carmen, Martín García, Lirio y HernándezRico, José Miguel. Derecho de la Publicidad (Navarra, Editorial Aranzadi, 2015), pp. 146-150 y más ampliamente Aguilar, Yolanda, cit. (n. 15), pp. 116-146 y GONZÁlEZ, Elisabet, cit. (n. 62), pp. 87-134.

${ }^{65}$ Sobre dicho principio en nuestro derecho véase IsLer, Erika. Derecho del consumo..., cit. (n. 22), pp. 102-138.

${ }^{66}$ Véase CIPP, cit. (n. 4), p. 9 y López, Patricia, La publicidad comercial..., cit. (n. 3), pp. 29-30. 
"la compra de bienes y contratación de servicios realizadas en reuniones convocadas o concertadas con dicho objetivo por el proveedor, en que el consumidor deba expresar su aceptación dentro del mismo día de la reunión" si estas se han convocado a través de un mensaje publicitario ${ }^{67}$. En el segundo, en cambio, se advierte la letra a) del artículo 3 de la LPC que consagra el derecho del consumidor a la libre elección del bien o servicio, al que se agregan argumentos específicos para cada una de las modalidades de publicidad agresiva que puedan presentarse. Así, la publicidad agresiva por coacción no sería lícita a partir de la proscripción de la fuerza moral o intimidación en la celebración de actos o contratos si es grave, injusta y determinante en los términos de los artículos 1456 y 1457 del Código Civil. Tratándose de la publicidad agresiva por influencia indebida si bien no está disciplinada en nuestro derecho es posible aproximarnos a ella a partir del desequilibrio contractual y la tutela del contratante débil ${ }^{68}$, dado que si el anunciante se aprovecha de una posición de poder para influir sobre el consumidor obstaculiza su libertad de elección, generando una asimetría procedimental y sustantiva que lo beneficia. Finalmente, el repudio a la publicidad agresiva por acoso se advierte en la consagración del derecho del consumidor a suspender los envíos de comunicaciones promocionales y/o publicitarias no deseadas reconocido en el artículo $28 \mathrm{~B}$ de la LPC, como lo revelan los casos en que nuestros tribunales se han pronunciado sobre este último precepto y la implementación del sitio NO MOLESTAR del Servicio Nacional del Consumidor (SERNAC) ${ }^{69}$.

Pues bien, tratándose del consumidor financiero podemos adicionar dos artículos que tutelan la libre elección del bien o servicio del consumidor y que disciplinan conductas que en el derecho comparado se consideran prácticas agresivas ${ }^{70}$ : el artículo $17 \mathrm{~F}$ relativo a envíos no solicitados y el artículo $17 \mathrm{H}$ letra a) referente a las ventas atadas.

${ }^{67}$ IsLER SOTO, Erika. Fuerza: prácticas de contratación y publicidad agresivas y tutela del consentimiento libre del consumidor, en VodanOVIC HaKLICKA, Antonio, Tratado de Derecho Civil. Fuentes de las Obligaciones. Parte General. Tomo 1. Actualización año 2019 (Santiago, Ediciones Jurídicas de Santiago, 2019), pp. 172-173.

${ }^{68}$ Sobre este tópico véase Gómez Calle, Esther, Desequilibrio contractual y tutela del contratante débil (Navarra, Editorial Aranzadi Thomson Reuters, 2018).

${ }^{69}$ Un análisis de todos ellos en LOPEZ, Patricia. La publicidad abusiva y agresiva..., cit. (n. 45), pp. 228-233, López DíAz, Patricia Verónica. La publicidad agresiva y la publicidad no deseada como límites al mensaje publicitario dirigido a los consumidores: una perspectiva teórica y práctica desde el derecho chileno en ISLER SOTO, Erika (ed.) GPS Consumo (Valencia, Tirant lo Blanch, en prensa) y López, Patricia, La publicidad comercial..., cit. (n. 3), pp. 38-39-

${ }^{70}$ Véase Aguilar, Yolanda, cit. (n. 15), pp. 142-144 y GonZÁLEZ, Elisabet, cit. 
El primero de ellos dispone que los proveedores de servicios o productos financieros y de seguros al público en general, no podrán enviar productos o contratos representativos de ellos que no hayan sido solicitados, al domicilio o lugar de trabajo del consumidor. Si bien es cierto que el precepto no se refiere expresamente a la publicidad comercial, se ha entendido que si la publicidad acompaña tal envío ella se torna ilícita ${ }^{71}$, precisamente porque afecta el derecho a la libre elección del consumidor configurándose, a nuestro juicio, un supuesto de publicidad agresiva por acoso si esta práctica se reitera, toda vez que se configura su supuesto de hecho: a través de la publicidad se presiona al potencial adquirente de un producto para comprarlo, impidiéndole que pondere la pertinencia de su decisión de consumo.

$\mathrm{El}$ artículo $17 \mathrm{H}$ letra a), en cambio, regula las denominadas ventas $\operatorname{atadas}^{72}$ y su tenor literal permite hacerlo extensivo a la publicidad comercial por dos motivos. De un lado, porque dicho precepto, en su parte pertinente, prohíbe a los proveedores de productos o servicios financieros "ofrecerlos" de manera atada, oferta que puede devenir en publicidad si además de ser seria, sincera, completa y manifestada provee información al consumidor con el propósito de persuadirlo de adquirir un producto o contratar un servicio financiero. Y, de otro, dado que el literal a) de este artículo entiende que dicha venta se verifica, entre otros supuestos, si el proveedor "impone al consumidor la contratación de otros productos o servicios adicionales, especiales o conexos", expresión que no sólo evidencia la falta de libertad de elección del consumidor sino que además denota una especie de coacción extrapolable a la publicidad y, por consiguiente, constitutiva de publicidad agresiva.

\section{LA TUTELA QUE DEBE DISPENSARSE AL CONSUMIDOR FINANCIERO FRENTE A LA PUBLICIDAD ENGAÑOSA Y A LA PUBLICIDAD AGRESIVA}

Asentada la procedencia y el alcance de la publicidad engañosa y de la publicidad agresiva respecto del consumidor financiero cabe preguntarse

(n. 57), pp. 120-122.

${ }^{71}$ Caballero Germain, Guillermo. Artículo $17 \mathrm{~F}$, en De la Maza, Iñigo- y Pizarro, Carlos (dirs.), Barrientos, Francisca (coord.), La Protección de los Derechos de los Consumidores. Comentario a la Ley de Protección a los derechos de los consumidores (Santiago, Editorial Thomson Reuters, 2013), p. 447.

${ }^{72}$ Sobre el alcance de este precepto véase Barrientos Camus, Francisca. Artículo 17 $H$, en De la Maza, Iñigo- y Pizarro, Carlos (dirs.), Barrientos, Francisca (coord.), La Protección de los Derechos de los Consumidores. Comentario a la Ley de Protección a los derechos de los consumidores (Santiago, Editorial Thomson Reuters, 2013), pp. 468-477. 
por la tutela que debe otorgársele frente al acaecimiento de tales ilícitos desde una perspectiva infraccional y civil, lo que exige examinar no sólo la LPC sino que también el Código Civil en lo que concierne a la publicidad agresiva por coacción.

La tutela de la publicidad engañosa, como consignamos más arriba, comprenderá, además de la multa infraccional prevista en el inciso segundo del artículo 24 de la LPC de hasta las 1.500 o 2.250 U.T.M., según el caso, la suspensión publicitaria, la publicidad correctiva, la indemnización de daños y la integración publicitaria, pudiendo el consumidor inclinarse por aquella que estime más conveniente en la medida que concurran sus requisitos de procedencia. Este ilícito publicitario se configurará a partir de la concurrencia de las condiciones objetivas signadas en el artículo 28 de la LPC y muy especialmente tratándose de aquellas contempladas en los artículo $3 \mathrm{~N}^{\circ} 38,3 \mathrm{~N}^{\circ} 40$ y $3 \mathrm{~N}^{\circ} 56$ de los Reglamentos sobre Información de Créditos Hipotecarios, de Créditos de Consumo y de Tarjetas de Crédito que podrán ser incorporadas al contrato celebrado en razón de ellas para activar la garantía legal disciplinada en los artículos 19, 20 y 21 de la LPC o algún mecanismo de tutela por incumplimiento. Ello sin perjuicio que el consumidor decida desechar tales alternativas de tutela civil e inclinarse por la nulidad relativa si puede acreditar dolo en los términos del referido artículo 28 de dicha Ley ${ }^{73}$.

Tratándose de la publicidad agresiva la tutela no sólo se encuentra en la LPC sino que, dependiendo del supuesto, también en el Código Civil. En efecto, resulta claro que se activa la multa infraccional de hasta 300 U.T.M. referida en el artículo 24 de la LPC que procede por vulneración de la libertad de elección prevista en el artículo 3 letra a) de la LPC, pudiendo aplicarse, según el caso, la agravante de la letra c) del artículo 24 cuando se daña la dignidad de los consumidores y la indemnización del inciso 2 del artículo 50 de la LPC que deviene en extracontractual. Pero a ellas se agregan la nulidad relativa si el consumidor celebra un contrato por coacción y ésta reúne los requisitos establecidos en los artículos 1456 y 1457 del Código Civil y, dependiendo del rol que se le asigne al desequilibrio contractual ocasionado por la influencia indebida, la nulidad absoluta, la nulidad relativa o la adaptación de contrato a opción del consumidor ${ }^{74}$.

${ }^{73}$ López, Patricia, Publicidad Engañosa. Indemnización de daños, cit. (n. 2), pp.195-210.

${ }^{74}$ Dependiendo si tal equilibrio se considera una cualidad esencial del objeto sobre el que recae un acto o contrato, un elemento de la esencia o una causal que determina la procedencia de dicha adaptación. Sobre este último tópico véase LOPEZ DíAz, Patricia Verónica. La adaptación del contrato como medio de tutela precontractual 
Pues bien, de todo lo dicho hasta acá, es posible sostener que existen al menos dos vías para alcanzar una tutela efectiva del consumidor financiero. Una es abordar el problema desde la perspectiva de la información, estableciendo deberes de consejo y adecuación a través del modelo de la corresponsabilidad en la recepción y comprensión de la información ${ }^{75}$. La otra, que no excluye a la primera sino que la complementa, es enfocarlo específicamente desde la publicidad comercial y, de un lado, exigir que la información contenida en ella se sujete a los principios de autenticidad y transparencia publicitaria y que contenga las advertencias necesarias para evitar que se configure una publicidad engañosa y, de otro, recurrir a la categoría de la publicidad agresiva para preservar la libertad de elección del consumidor respecto del producto financiero que pretende adquirir o del servicio financiero que desea contratar. Podría pensarse que esta segunda vía que proponemos requiere de una ley que consagre expresamente tales principios y tipifique la publicidad agresiva, pero, como hemos pretendido demostrarlo en estas líneas, es perfectamente posible construir aquellos y sustentar la procedencia de tal ilícito publicitario a partir de una interpretación armónica de determinados artículos contenidos en la LPC y de los artículos 1456 y 1457 del Código Civil en lo que atañe a la nulidad relativa derivada de la publicidad agresiva por coacción.

\section{CONCLUSIONES}

De lo expresado en los párrafos precedentes es posible arribar a las siguientes conclusiones:

1. El consumidor financiero presenta una vulnerabilidad adicional a aquella estructural propia de todo consumidor atendida su condición socioeconómica y educacional, deviniendo, por regla general, en hipervulnerable, motivo por el cual ha concitado la especial atención de nuestro legislador como lo evidencian los artículos 17A a 17M y 62 de la LPC y los Reglamentos sobre Información de Créditos Hipotecarios, de Créditos de Consumo y de Tarjetas de Crédito, algunos de cuyos preceptos hemos examinado en este artículo.

en el Código Civil chileno, en Revista de Derecho de Valdivia $31 \mathrm{~N}^{\circ} 1$ (2018), pp. 127-157.

${ }^{75}$ Goldenberg, Juan, El sobreendeudamiento y los paradigmas..., cit. (n.10), pp. 14-20. 
2. Dicha regulación no sólo versa sobre la información que debe proporcionársele sino que también comprende aquella contenida en la publicidad comercial de la que es destinatario, evidenciando un repudio de la publicidad engañosa y proporcionando los insumos dogmáticos necesarios que permiten alcanzar dos objetivos de trascendental importancia: perfeccionar el contenido de la publicidad engañosa a través de determinadas condiciones objetivas sobre las que ella puede recaer y sustentar la procedencia del principio de veracidad, del principio de transparencia publicitaria y de la publicidad agresiva por acoso, coacción e influencia indebida.

3. La configuración de la publicidad engañosa y de la publicidad agresiva, así como de la tutela que debe otorgársele al consumidor financiero frente al acaecimiento de ambos ilícitos constituyen, respectivamente, un mecanismo disuasivo y un mecanismo represivo que contribuye a fortalecer la protección de dicho consumidor, cuya procedencia no requiere de ley expresa que los contemple sino de un esfuerzo interpretativo de determinados artículos contenidos en la LPC y en nuestro Código Civil como el que hemos efectuado en esta investigación.

\section{BiBLIOGRAFÍA}

Aguilar Olivares, Yolanda. Las prácticas agresivas desleales en el mercado y la tutela del consumidor (Navarra, Editorial Aranzadi, 2020).

Baquero Herrera, Mauricio y Caballero Germain, Guillermo. Artículo $17 G$ en De la Maza, Iñigo- y Pizarro, Carlos (dirs.), Barrientos, Francisca (coord.), La Protección de los Derechos de los Consumidores. Comentario a la Ley de Protección a los derechos de los consumidores (Santiago, Editorial Thomson Reuters, 2013).

Barocelli, Sergio Sebastián. Hacia la construcción de la categoría de consumidores hipervulnerables en BAROCELLI, Sergio Sebastián (dir.), Consumidores Hipervulnerables (Buenos Aires, El Derecho, 2018).

Barrientos Camus, Francisca. Artículo $17 \mathrm{H}$, en De la Maza, Iñigo- y Pizarro, Carlos (dirs.), Barrientos, Francisca (coord.), La Protección de los Derechos de los Consumidores. Comentario a la Ley de Protección a los derechos de los consumidores (Santiago, Editorial Thomson Reuters, 2013).

Barrientos Camus, Francisca. Lecciones de derecho del consumidor (Santiago, Thomson Reuters, 2019).

Caballero Germain, Guillermo. Artículo 17 F, en De la Maza, Iñigo- y Pizarro, Carlos (dirs.), Barrientos, Francisca (coord.), La Protección de los Derechos de los Consumidores. Comentario a la Ley de Protección a los derechos de los consumidores (Santiago, Editorial Thomson Reuters, 2013).

De la Maza Gazmuri, Iñigo. Artículo 28, en De la Maza, Iñigo- y Pizarro, Carlos (dirs.), Barrientos, Francisca (coord.), La Protección de los Derechos de los Consumidores. Comentario a la Ley de Protección a los derechos de los consumidores (Santiago, Editorial Thomson Reuters, 2013). 
De la Maza Gazmuri, Iñigo. La información como técnica de protección de los consumidores: créditos hipotecarios ¿una paradoja regulatoria?, en VIDAL, Álvaro; SEVERIN, Gonzalo; MejíAs, Claudia (editores), Estudios de Derecho Civil X (Santiago, Editorial Thomson Reuters, 2015).

De la MAZA, Iñigo. La ley 20.555: oportunidad y pulcritud, en Análisis Jurídico, Mercurio Legal, 9 de julio de 2012, disponible en https://www.elmercurio.com/ Legal/Noticias/Analisis-Juridico/2012/07/09/La-ley-20555-oportunidad-y-pulcritud.aspx. [fecha de consulta: 16 de septiembre de 2020].

De la Maza Gazmuri, Iñigo. Publicidad engañosa: noción amplia y consecuencias, ponencia presentada en las IX Jornadas Nacionales de Derecho de Consumo, organizadas por la Universidad Arturo Prat, Iquique, 2019.

FernÁNDEZ Fredes, Francisco. Manual de Derecho Chileno de Protección del Consumidor (Santiago, Lexis Nexis, 2003).

Fernández Acevedo, Fernando. Artículo 17L, en De la Maza, Iñigo- y Pizarro, Carlos (dirs.), Barrientos, Francisca (coord.), La Protección de los Derechos de los Consumidores. Comentario a la Ley de Protección a los derechos de los consumidores (Santiago, Editorial Thomson Reuters, 2013).

Goldenberg Serrano, Juan Luis. Los contornos del deber de consejo como expresión de la colaboración y como técnica de protección, Revista de Derecho Universidad de Concepción, Vol. 86, № 244 (2018).

Goldenberg SERRANO, Juan Luis. Herramientas del big data y del fintech para prevenir $y$ aliviar el sobreendeudamiento del consumidor: una propuesta, en Revista Chilena de Derecho y Tecnología 8, N² (2019).

Goldenberg Serrano, Juan Luis. El sobreendeudamiento y los paradigmas del consumidor financiero responsable y del proveedor financiero profesional, en: Revista Ius et Praxis 26, $\mathrm{N}^{\circ} 1$ (2020).

Goldenberg SerRano, Juan Luis. El propósito persuasivo de la publicidad y sus peligros en el ámbito del crédito al consumo, en Revista Chilena de Derecho Privado 34 (2020).

Goldenberg Serrano, Juan Luis. El crédito de consumo ofrecido al consumidor vulnerable: el deber de adecuación como parte de un modelo de corresponsabilidad del proveedor en Elorriaga, Fabián (coord.), Estudios de Derecho Civil XV (Santiago, Editorial Thomson Reuters, 2020).

González Cazorla, Fabián, Daño moral en el derecho del consumidor (Santiago, Editorial Der, 2019).

GonZÁlez Pons, Elisabet. Prácticas agresivas y tutela del consumidor (Madrid, Boletín Oficial del Estado, 2019).

Gómez Calle, Esther. Desequilibrio contractual y tutela del contratante débil (Navarra, Aranzadi Thomson Reuters, 2018).

Hernández Díaz- Ambrona, María Dolores, Consumidor vulnerable (Madrid, Editorial Reus, 2016).

Hernández Paulsen, Gabriel. La obligación precontractual de la entidad financiera de informar al cliente, especialmente a la luz de la Ley de Protección de los Derechos de los consumidores" en VIDAL, Álvaro; SEverin, Gonzalo; Mejías, Claudia (editores), Estudios de Derecho Civil X (Santiago, Editorial Thomson Reuters, 2015).

Hualde Manso, Teresa. Consumidor medio y consumidor vulnerable, en Hualde Teresa, Del consumidor informado al consumidor real. El futuro del Derecho de consumo europeo (Madrid, Editorial Dykinson, 2016). 
IsLer Soto, Erika Marlene. Aproximación a la publicidad engañosa, desde la perspectiva de la competencia desleal y la protección al consumidor", en Revista Ars Boni et Aequi $6 \mathrm{~N}^{\circ} 1(2010)$.

IsLer Soto, Erika. La relatividad de los derechos subjetivos de los consumidores", en Revista Derecho de Valdivia 24, No 2 (2011).

Isler Soto, Erika. Artículo 31, en De la Maza, Iñigo- y Pizarro, Carlos (dirs.), Barrientos, Francisca (coord.), La Protección de los Derechos de los Consumidores. Comentario a la Ley de Protección a los derechos de los consumidores (Santiago, Editorial Thomson Reuters, 2013).

ISLER SOTO, Erika. Fuerza: prácticas de contratación y publicidad agresivas y tutela del consentimiento libre del consumidor, en Vodanovic HaKLicKa, Antonio, Tratado de Derecho Civil. Fuentes de las Obligaciones. Parte General. Tomo 1. Actualización año 2019 (Santiago, Ediciones Jurídicas de Santiago, 2019).

Ister Soto, Erika. Derecho del consumo. Nociones fundamentales (Valencia, Editorial Tirant lo Blanch, 2019).

IsLer Soto, Erika. Acerca del reconocimiento de los consumidores hipervulnerables, en VÁsquez, María Fernanda (dir.) Estudios de Derecho Comercial, X Jornadas Nacionales de Derecho Comercial (Valencia, Editorial Tirant lo Blanch, 2020).

Leiñena Mendizabal, Elena y Irákulis Arregi, Nerea, La regulación jurídica de la publicidad financiera, Estudios sobre Consumo N80 (2007), pp. 9-28.

Lema Devesa, Carlos y Fernando Magarzo, María del Rosario. La publicidad Financiera en Lema Devesa, Carlos, Problemas jurídicos de la publicidad (Madrid, Marcial Pons, 2007).

López Díaz, Patricia Verónica. Publicidad Engañosa. Indemnización de daños. Concurrencia de responsabilidad civil. Opción de responsabilidades. Responsabilidad Extracontractual. Corte Suprema, 18 de enero de 2018, rol 73907-2016, en Revista Chilena de Derecho Privado 30 (2018), pp. 195-210.

López DíAz, Patricia Verónica. La adaptación del contrato como medio de tutela precontractual en el Código Civil chileno, en Revista de Derecho de Valdivia 31 N$^{\circ} 1$ (2018).

López Díaz, Patricia Verónica ¿Es la obligación/deber de advertencia una categoría exclusiva de la Ley 19.496?: hacia una justificación dogmática y propuesta de construcción en el Código Civil chileno, en: Gómez, Maricruz; HernándeZ, Gabriel; Lathrop, Fabiola, TAPIA; Mauricio (edits.), Estudios de Derecho Civil XIV (Santiago, Editorial Thomson Reuters, 2019).

López DíAz, Patricia Verónica. La publicidad abusiva y agresiva: un intento de confguración dogmática en el derecho chileno y la tutela de los consumidores frente a tales prácticas comerciales, en VÁSQUEZ PaLMA, María Fernanda (dir.) Estudios de Derecho Comercial, X Jornadas Nacionales de Derecho Comercial (Valencia, Editorial Tirant lo Blanch, 2020).

López DíAz, Patricia Verónica. La publicidad agresiva y la publicidad no deseada como limites al mensaje publicitario dirigido a los consumidores: una perspectiva teórica y práctica desde el derecho chileno en IsLER SOTO, Erika (ed.) GPS Consumo (Valencia, Tirant lo Blanch, en prensa).

López DíAz, Patricia Verónica. La publicidad comercial como fenómeno jurídico: una aproximación general desde el derecho chileno, en Revista Ius et Praxis 26, $\mathrm{N}^{\circ} 3$ (2020).

López Díaz, Patricia Verónica. La tutela de la publicidad engañosa: un intento de sistematización desde el derecho civil chileno, en Elorriaga, Fabián et al. (edits.), Estudios de Derecho Civil XV (Santiago, Editorial Thomson Reuters, 2020). 
López Díaz, Patricia Verónica. La publicidad abusiva como ilícito que vulnera la integridad del consumidor e infringe el derecho a la seguridad en el consumo previsto en el artículo 3 letra d.) de la LPC, en IsLer Soto, Erika (editora), Seguridad y conformidad en el derecho de consumo: reflexiones actuales (Valencia, Tirant Lo Blanch, en prensa).

Martínez Escribano, Celia, Herrero Suárez, Carmen, Martín García, Lirio y Hernández-Rico, José Miguel. Derecho de la Publicidad (Navarra, Editorial Aranzadi, 2015).

Massaguer, José. Las prácticas agresivas como actos de competencia desleal, Revista Actualidad Jurídica Uría Méndez 27 (2010).

Momberg Uribe, Rodrigo. El rol de la publicidad en la etapa precontractual de los negocios de consumo y su relación con el principio de buena fe, en CORRAL, Hernán y RodríGuez, María Sara (coords.), Estudios de Derecho Civil II (Santiago, Editorial Lexis Nexis, 2007).

Rojas Covarrubias, Nicolás ¿Es el consumidor un mal padre de familia? Alcance del deber de cuidado exigible a los consumidores" en VIDAL, Álvaro; SEVERIN, Gonzalo; MejÍAs, Claudia (editores), Estudios de Derecho CivilX (Santiago, Editorial Thomson Reuters La Ley, 2015).

Yáñez Rebolledo, María Paz. Protección al consumidor financiero en Chile. Mi experiencia como árbitro y mediadora del Sernac Financiero, en Carrasco, Humberto (edit.), Estudios de Derecho del Consumidor (Santiago, Rubicón Editores, 2018)

San Martín Neira, Lilian. Artículo $3^{\circ}$ inciso $2^{\circ}$, en Iñigo De la Maza, Carlos PizaRRO (edits.), Francisca BARrientos (coord.). La Protección de los Derechos de los Consumidores. Comentario a la Ley de Protección a los derechos de los consumidores (Santiago, Editorial Thomson Reuters, 2013).

San Martín Neira, Lilian, El "deber de aviso" ante la ocurrencia de un caso fortuito o fuerza mayor ¿tiene aplicación en Chile? en ElorRIAGa, Fabián (coord.), Estudios de Derecho Civil VII (Santiago, AbeledoPerrot Thomson Reuters, 2012).

Vilajoana, Sandra Alejandre. Las Leyes de la publicidad. Limites jurídicos de la actividad publicitaria (Barcelona, Editorial Universitat Oberta de Catalunya, 2011).

\section{JURISPRUDENCIA}

Corte de Apelaciones de Santiago, "Servicio Nacional del Consumidor con Banco Consorcio", 15 de enero de 2014, Rol 1687-2013 (recurso de apelación), no disponible en buscador digital.

Segundo Juzgado de Policía Local de Las Condes, "SERNAC con Travel Security S.A”, 25 de junio de 2014, Rol 23048-5/2014.

Primer Juzgado Civil de Vitacura, “SERNAC con Klassik Car S.A.”, 19 de noviembre de 2014, Rol 410359-8/2014.

Segundo Juzgado de Policía Local de Las Condes, "Sernac con Lan Tours División de Servicios Terrestres S.A.”, 9 de marzo de 2015, Rol 23049-10/2014,

Primer Juzgado de Policía Local de Las Condes, "SERNAC con Turismo Cocha S.A.”, 7 de agosto de 2015, Rol 1899-8/2015,

Segundo Juzgado de Policía Local de Providencia, "SERNAC con Distribuidora de Industrias Nacionales S.A.”, 7 de agosto de 2015, Rol 5380-F/2015, 
Segundo Juzgado de Policía Local de Las Condes "Sernac con Cencosud Retail S.A. y Cencosud Administradora de Tarjetas S.A.”, 23 de marzo de 2015, Rol 42109-5/2014.

Cuarto Juzgado de Policía Local de Santiago, "SERNAC con Banco de Chile”, 30 de marzo de 2016, Rol 14114-5/2015.

Segundo Juzgado de Policía Local de Las Condes, "SERNAC con Mitsui Auto Finance Chile Limitada", 15 de noviembre de 2017, Rol 47088-5/2017.

Segundo Juzgado de Policía Local de Las Condes "SERNAC con Importadora DESMO Limitada y Tanner Servicios Financieros S.A.”, 13 de marzo de 2018, Rol 55057-10/2017.

Corte de Apelaciones de Antofagasta, "Álvarez con Falabella", 16 de junio de 2016, Rol119-2016.

Juzgado de Policía Local de Las Condes, "Servicio Nacional del Consumidor con "Banco Créditos", 27 de junio de 2017, Rol 23080-2016-8 (recurso de apelación), no disponible en buscador digital.

CONAR, "De oficio con Nissan Chile SpA", 15 de abril de 2002, Rol 1137/2020, disponible en https://www.conar.cl/wp-content/uploads/2020/04/Rol-1137-Fallo-Conar.pdf. [fecha de consulta: 14 de septiembre de 2020]. 